\begin{abstract}
Title of Thesis:

THE ROLE OF FEMININE AND MASCULINE NORMS IN COLLEGE WOMEN'S ALCOHOL USE

Aylin Esra Kaya, Master of Arts, 2016

Thesis directed by:

Dr. Derek Kenji Iwamoto, Department of Psychology

Current literature suggests not only that men and women can conform to both feminine and masculine norms, but that women who adhere to certain masculine norms may be at greater risk for problematic alcohol use. This study examined conformity to both masculine and feminine norms, and how conformity to distinct norms influenced heavy episodic drinking and alcohol-related problems among a sample of underage college women $(N=645)$. Results demonstrated that the masculine norms risk-taking and emotional control were associated with increased HED, while the masculine norm power over women was associated with a decrease in HED. Traditional feminine norms, including modesty and sexual fidelity, were associated with a decrease in HED and alcohol-related problems. The feminine norm relational was associated with increased HED, while the norms thinness and appearance were associated with increased alcohol-related problems. The study's theoretical and clinical implications are discussed.
\end{abstract}




\title{
THE ROLE OF FEMININE AND MASCULINE NORMS IN COLLEGE WOMEN'S ALCOHOL USE
}

by

\author{
Aylin Esra Kaya \\ Thesis submitted to the Faculty of the Graduate School of the \\ University of Maryland, College Park, in partial fulfillment \\ of the requirements for the degree of \\ Master of Arts \\ 2016
}

Advisory Committee:

Derek Kenj Iwamoto, Ph.D., Chair

Richard Shin, Ph.D.

Karen O'Brien, Ph.D. 
C Copyright by Aylin Esra Kaya 


\section{Table of Contents}

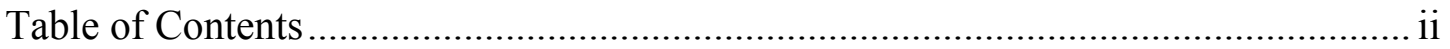

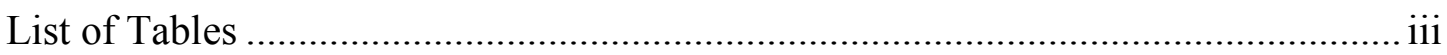

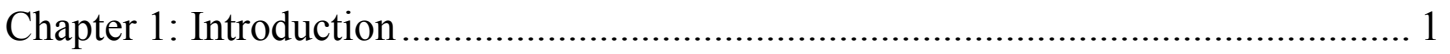

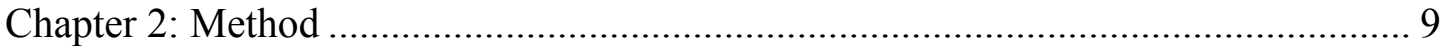

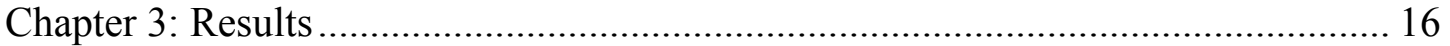

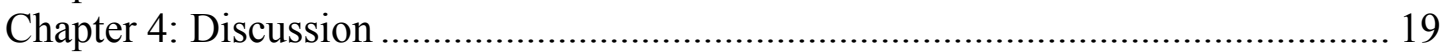

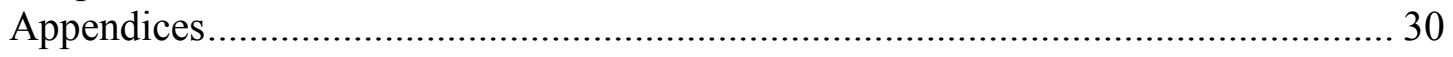

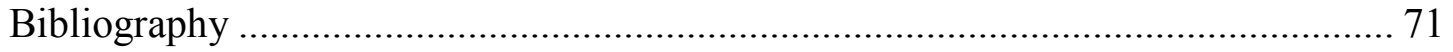




\section{List of Tables}

Table 1: Model Results of Negative Binomial Regression.......................... 30 


\section{Chapter 1: Introduction}

In the United States, alcohol use among college students is a significant public health problem. Several epidemiological studies have found that the vast majority of college students consume moderate amounts of alcohol, and over half of college-aged drinkers drink to get drunk at least once a week (DuRant et al., 2008; Hingson, Heeren, Winter, \& Wechsler, 2005). In particular, heavy episodic drinking (HED), or consuming at least 5 or 4 drinks in a 2-hour sitting for men and women respectively, has been associated with a number of negative consequences (Hingson, Heeren, \& Zakocs, 2002; Hingson, Heeren, Zakocs, Winter, \& Wechsler, 2003; Parks \& FalsStewart, 2004). Underage drinkers represent a particularly vulnerable subpopulation of college students that may be at increased risk for problematic alcohol use.

Although underage drinkers consume alcohol less frequently than adults, they consume more drinks per sitting (Hingson \& White, 2014). Underage drinking plays a substantial role in traffic deaths, suicides, homicides, alcohol poisoning, risky sexual behavior, physical and sexual assaults, other various nonfatal injuries, as well as death by falls, burns, and drowning (U.S. Department of Health and Human Services, 2007). Furthermore, episodes of heavy drinking can heighten underage drinkers' susceptibility to experience a host of negative alcohol-related problems that can impair long-term functioning. Given the prevalence of heavy episodic drinking and its detrimental health consequences, it is important to elucidate factors that heighten risk for problematic alcohol use.

An important finding to note is that while men's drinking rates are generally higher than women's, there is emerging evidence that suggests women's drinking 
rates may be converging with men's (Keyes, Grant, \& Hasin, 2008). Some researchers speculate that the increase in alcohol consumption among college-aged women might be reflective of women's changing role in society (Keyes, Grant, \& Hasin, 2008; Lyons, 2009). Several scholars note that over the past thirty years, women have had more access to traditionally male-dominated public domains, and thus have also had the opportunity to engage in stereotypically masculine activities, such as public drinking (Keyes et al., 2008; Lyons \& Willott, 2008; Wilsnack et al., 2000). Thus, as women have moved away from constrictive notions of femininity, drinking has become linked with empowerment, pleasure seeking, and independence (Hutton, 2004; Lyons \& Willott, 2008). Additionally, because heavy drinking is linked to notions of masculinity, evidence suggests that young women who strive to be more masculine may engage in heavier drinking (Young et al., 2005).This increase in young women's alcohol use presents a significant public health concern given that heavy drinking more severely affects women than it does men, due to biological differences that make intoxication quicker for women. Women tend to be physically smaller than men (Nolen-Hoeksema \& Hilt, 2006), store less body water, and have lower levels of alcohol metabolizing enzymes, making blood alcohol levels higher than men's, even when consuming fewer alcoholic drinks (Frezza et al., 1990; Jones \& Jones, 1976). Women are also at an elevated risk compared to men for developing health problems, including liver cancer, breast cancer, accelerated brain atrophy, and cognitive deficits due to heavy alcohol consumption (Acker 1986; Loft et al., 1987; Wilsnack \& Wilsnack, 2014). 
Given young women's converging drinking rates with men, and the myriad of health consequences associated with this increased alcohol consumption, it is critical to understand the potential role of gender-relevant factors in problematic drinking among this at-risk group. The purpose of this study was to examine the role of distinct masculine and feminine norms on heavy episodic drinking and alcohol-related problems among underage college women, specifically to understand which distinct gender norms are significantly associated with these outcomes.

\section{Gender, Health, and Women's Changing Roles in Society}

Gender norms provide implicit guidelines and constraints for how individuals think, act, and feel (Mahalik et al., 2005). Contemporary researchers have identified a number of feminine norms associated with hegemonic definitions of femininity that are upheld through modeling and reinforcement. These traditional norms include pursuing a thin body ideal, being modest about one's accomplishments, being domestic, wanting to care for children, investing in romantic relationships, being sexually monogamous, committing resources to maintaining an attractive appearance, and being pleasant and nice (Mahalik et al., 2005; Parent \& Moradi, 2010). It has been noted that gender norms from privileged groups in society create the dominant norms that affect and shape the experiences of individuals from marginalized groups in society as well (Mahalik et al., 2003).

Similar to other forms of social identity, women and men express their gender identity through outward behaviors, including health-impacting behaviors (Lyons, 2009; Saltonstall, 1993). Within this literature, alcohol consumption has been investigated in relation to gender, with many arguing that HED is a gendered activity 
(Lyons, 2009). Cross-culturally, men drink more heavily and frequently than women, and heavy drinking is considered to be characteristic of hegemonic masculinity (Lemle \& Mishkind, 1989; Rahav, Wilsnack, Bloomfield, Gmel, \& Kuntsche; 2006; Van Gundy, Schieman, Kelley, \& Rebellon, 2005). This may be because for men, a way of proving masculinity may be through practices that put their health at risk, such as consuming large amounts of alcohol, refusing to seek professional help, engaging in risky sexual behaviors, and acting violently (Courtenay, 2000; Lyons, 2009; Mahalik et al., 2007). In contrast, health promoting behaviors have generally been linked to traditional notions of femininity, as women are expected to assume responsibility for caring for others, seek professional care and self-help, and are also expected to be concerned with health and nutrition (Bordo, 1993; Lee \& Owens, 2002). However, given the increased prevalence of HED in underage women, it would appear that gendered notions of health seeking behaviors might not thoroughly explain heavy alcohol consumption among underage women. Therefore, a more nuanced understanding of gender norm conformity may help explain within-group differences with regard to women's alcohol consumption.

While gender has traditionally been measured as a unidimensional construct, several studies have examined multidimensional gender norms and alcohol use. For instance, emerging research has highlighted that endorsement of distinct feminine norms, including sexual fidelity, domesticity, and valuing romantic relationships were associated with less drinking among samples of Spanish and Romanian young adult women (Brabete, Sanchez-Lopez, Cuellar-Flores, \& Rivas Diez, 2013; SanchezLopez, Cuellar-Flores, \& Dresch, 2012). Among a sample of Asian American 
women, feminine norms related to investment in personal relationships, as well as investment in one's appearance, were positively associated with heavy episodic drinking and alcohol-related problems, whereas traditional feminine norms including modesty and sexual fidelity were strongly associated with less heavy episodic drinking and alcohol-related problems (Iwamoto et al., 2015). Collectively, these findings indicate that certain traditional aspects of femininity may prevent excessive drinking, perhaps because women who do not want to be seen as gender nonconforming, or non-feminine, may limit the amount they drink (Peralta, 2007). Furthermore, women who conform to traditionally stereotypical feminine norms, including being nurturing and caring for children, may find heavy drinking and intoxication to be incompatible with these norms (Ricciardelli, Connor, Williams, \& Young, 2001).

\section{The Present Study}

Although the research reviewed has focused on the association between endorsement of feminine norms and alcohol use, it has also been noted that women and men can enact both masculinity and femininity (Bem, 1974; Smiler, 2004). Psychological androgyny, or the expression of both masculine and feminine traits, has been studied in order to address different gender norm endorsement (Gilbert, 1981), and its impact on health outcomes. Theorists have posited that individuals who are gender nonconforming have optimal mental health (Taylor \& Hall, 1982), given that

conforming to strict gender identities can be inhibiting (Woodhill \& Samuels, 2004), and because certain gender norms are inherently dysfunctional, such as restrictions on men's emotionality (Mahalik et al., 2003). 
In light of research linking gender nonconformity to optimal health, researchers have begun to assess both feminine and masculine norms among samples of men and women, with more research focusing on masculine norms among women (Iwamoto \& Smiler, 2013). This is a significant area of research given that men and women can both enact masculinity (Parent \& Smiler, 2013), and this enactment may have significant implications for heath-related behaviors. Research also highlights that the construct of masculinity functions similarly for men and women, such that women's understanding of masculinity is similar to that of men's (Parent \& Smiler, 2013).

Research by Steinfeldt and colleagues' (2011) highlights the impact of adherence of masculine norms on the health behaviors of college women athletes. Results indicated that the masculine norm risk-taking was linked to positive outcomes such as body esteem, perhaps because the risk-taking norm may contribute to increased confidence in relation to athletics and physical competence. Yet the researchers also note that this same norm has been linked to negative outcomes among men, such as heavy episodic drinking, implying that conformity to gender norms differ across contexts, as well as genders (Steinfeldt et al., 2011). In another study among adolescent girls and boys, girls who endorsed masculine norms including risk-taking and playboy norms were more likely to report alcohol use (Iwamoto \& Smiler, 2013). Thus, endorsement of masculine norms might explain additional variance in alcohol consumption for women as well as men.

These studies present a complex picture of how masculine norms may influence women's health-related behaviors. However, no study to date has examined 
how endorsing both masculine and feminine norms is related to alcohol use and alcohol-related problems among a sample of young adult U.S. women. This may be an important direction for this field of research because women can conform to masculine gender norms in addition to feminine norms (Parent \& Smiler, 2013), and studying women's conformity to masculine norms may help explain why certain women engage in more drinking than others. Indeed, Rahav and colleagues (2006) note that in societies where there is a less of a gendered gap between men and women's social statuses, women consume alcohol at more comparable rates to men. In certain social contexts, women may feel pressure to conform to masculine norms, because they perceive these norms may allow access to higher social status (Parent \& Moradi, 2010). Because of this pressure, women who conform to certain masculine norms may in turn experience more negative health outcomes. This may imply that women's conformity to certain masculine norms or expectations helps them "get ahead" socially, while the pay-off may be increased alcohol use and subsequent alcohol-related problems.

The present study advances this body of literature by assessing both feminine and masculine norms to gain a deeper understanding of the distinct effects these norms have on HED and alcohol-related problems among underage college women. This population is important to study given women's increasing drinking rates and substantial alcohol-related consequences (Keyes, Grant \& Hasin, 2008). In addition to multidimensional gender norms, the study included two well-established correlates of drinking among underage women: sorority status and perceived peer alcohol use, to determine whether gender norm conformity explained alcohol use and alcohol-related 
problems above and beyond these variables (Borsari, Murphy, \& Barnett, 2007; Capone, Wood, Borsari, \& Laird, 2007). Based on previous research, we hypothesized that the masculine norms that serve as risk and protective factors for men would act equivalently for women. Specifically, we predicted that the masculine norms risk-taking, playboy, and power over women, which have been reported as risk factors for HED for men, and the norms self-reliance, heterosexual presentation, and emotional control which have been reported as protective against heavy drinking for men, would correspondingly be risk and protective factors for women (Iwamoto, Corbin, Lejuez, \& MacPherson, 2014). Based on previous research, we also hypothesized that distinct feminine norms including modesty and sexual fidelity would be associated with decreased alcohol outcomes, whereas, the feminine norms of being invested in one's appearance and thinness would be associated with increased alcohol outcomes (Iwamoto et al., 2015). 


\section{Chapter 2: Method}

\section{Participants and Procedure}

Participants included 667 freshman undergraduate women $(M$ age $=18.47, S D$ $=.53$ ) at a large public university. The sample was approximately $53 \%$ White, $19 \%$ Asian or Asian American, 13\% African American, and 15\% biracial or other. As the study focused on underage drinking, participants had to be freshmen between the ages of 18-20 to participate, and those who were not in this age range, or who were not freshmen enrolled at the university, did not qualify for participation.

Institutional Review Board approval was obtained prior to data collection. The university's registrar provided us with a random sample of $30 \%$ of incoming

freshmen, and potential participants were emailed the survey link through this listserv or after having signed up for participation during a university-wide research fair, as well as recruited through flyers that were posted in academic buildings on campus. Participants who completed the survey were compensated $\$ 20$, and participants who did not complete at least $75 \%$ of the responses for variables of interest were excluded from the data analysis $(n=22)$, bringing the final number of participants to 645 . We approximated participants' missing data by using full information maximum likelihood estimation during the data analysis, which is discussed further in the method section.

\section{Measures}

Demographics. The collected demographic information included gender, age, and race/ethnicity. 
Greek status. A demographic item to assess for Greek involvement was included. Participants responded to the question, "Do you belong to a sorority?" with responses being "Yes," "No," or "Plan to." The responses "Yes" and "Plan to" were both coded as (1), while the response "No" was coded as 0 for the data analysis. In the sample, $29.3 \%$ of women $(n=189)$ reported either being, or planning to be, in a sorority.

Perceived peer norms. This instrument is based on the modified version of the Drinking Norms Rating Form (DNRF; Baer, Stacy, \& Larimer, 1991; Corbin, Iwamoto \& Fromme, 2011), which assesses participants' college students' perception of peers' weekly alcohol consumption. The perceived peer norms score was determined by averaging the perceived weekly consumption for women and men in that participant's peer group. Participants were asked to estimate peer alcohol use distinctly for both men and women in their groups, rather than collapsing men's and women's perceived alcohol use. This measure has been repeatedly used among college students, and in the present study, the reliability estimate for this measure was .80 for male peer norms, and .78 for female peer norms.

\section{Conformity to Masculine Norms Inventory (CMNI-29). Endorsement of} multidimensional masculine norms was measured with the CMNI-29 (Hsu \& Iwamoto, 2014). This measure captures the extent to which an individual endorses specific subsets of masculinity as they pertain to U.S. hegemonic (white, heterosexual, middle class) culture. The original measure, the CMNI, is a 94-item measure developed by Mahalik and colleagues (2003), and has demonstrated strong psychometric and construct validity evidence. Its abbreviated version, the CMNI-46 
was developed by Parent and Moradi (2009), and the CMNI-29 is a brief version of the CMNI-46, and was developed in order to provide a more valid assessment of conformity to masculine norms among diverse racial groups, particularly Asian American and White men. The CMNI-29 consists of 8 subscales: (1) winning ("Winning is not my first priority"), (2) playboy ("If I could, I would frequently change sexual partners"), (3) self-reliance ("I hate asking for help"), (4) violence ("I am disgusted by any kind of violence"), (5) heterosexual presentation ("I would be furious if someone thought I was gay"), (6) risk-taking ("I enjoy taking risks"), (7) emotional control ("I like to talk about my feelings"; this item was reverse scored, as this subscale refers to emotional repression), and (8) power ("Women should be subservient to men"). Each item is scored on a Likert scale, with the responses ranging from 0 ("strongly disagree") to 3 ("strongly agree"). Higher scores on each subscale indicate greater endorsement of the respective norm. The CMNI-46 has been shown to have metric invariance among samples of women, indicating that it is a psychometrically appropriate measure of women's masculine norm conformity (Parent \& Smiler, 2013). In this sample, internal reliability estimates of the CMNI-29 subscales ranged from .70 to .85 .

\section{Conformity to Feminine Norms Inventory (CFNI-45). Endorsement of} feminine norms was measured with the abbreviated version of the original CFNI, the CFNI-45 (Parent \& Moradi, 2010; Mahalik et al., 2005). The CFNI was designed to conceptually describe the salient expectations and beliefs associated with femininity in U.S. hegemonic culture, and to what extent an individual endorses specific feminine norms. The CFNI-45 (Parent \& Moradi, 2010) captures 9 subscales 
including: (1) sweet and nice ("Being nice to others is extremely important"), (2) thinness ("I would be happier if I was thinner"), (3) modesty ("I hate telling people about my accomplishments"), (4), domesticity ("It is important to keep your living space clean"), (5) care for children ("Taking care of children is extremely fulfilling"), (6) relational ("I make it a point to get together with my friends regularly"), (7) invest in appearance ("I spend more than 30 min a day doing my hair and make-up"), (8) sexual fidelity ("I would only have sex with the person I love"), and (9) romantic relationship ("Being in a romantic relationship is important”). The responses are recorded on a 4-point scale $(0=$ "strongly disagree" to $3=$ "strongly agree $)$, with higher scores indicating greater conformity to specific feminine norms. In this sample, internal reliability estimates for the CFNI-45 subscales ranged from .67 to 90. All correlations for these variables are reported in Table 1.

Heavy episodic drinking (HED). Heavy episodic drinking was assessed with the question "During the last three months, how many times did you have 4 or more drinks in a 2-hour sitting?" This measure of HED has frequently been used to study binge drinking among college students, including college freshmen, with 4 drinks in a 2-hour sitting being noted as the appropriate standard of binge drinking for women, specifically (Wechsler \& Isaac, 1992; Wechsler et al., 1995). Participants recorded their own responses in order to obtain more accurate frequency counts.

Alcohol-related problems. Alcohol-related problems were measured by the Brief Young Adult Alcohol Consequences Questionnaire (B-YAACQ; Kahler, Strong, \& Read, 2005), a 24-item measure assessing alcohol consequences in line with symptoms of alcohol abuse and dependence as defined by the DSM-IV. This 
questionnaire is an abbreviated version of the original YAACQ, a 48-item measure.

The original measure was shortened to more efficiently assess alcohol consequences among underage college students, as well as to eliminate redundant items, and to ensure that the measure was not gender biased for all 24 items. The B-YAACQ assesses consequences that have been experienced over the past year, and are all worded in the first person, with the possible responses being "Yes" or "No." Sample items include "I have passed out from drinking," "I have not gone to work or missed classes at school because of drinking, a hangover, or illness caused by drinking," and "I have been overweight because of drinking." The internal reliability estimate in this sample was .90 .

\section{Data analytic plan}

In order to address missing data, we used full information maximum likelihood estimation (FIML), which estimates parameters of missing data by computing a casewise likelihood function based on observed variables for each case (Olinsky, Chen, \& Harlow, 2003). Stimulation studies using FIML in comparison with other imputation techniques have found that FIML produces approximately unbiased results across a variety of parameter estimates, making FIML one of the preferred methods for addressing missing data (e.g. Enders \& Bandalos, 2001;

Schlomer, Bauman, \& Card, 2010). FIML was conducted after excluding participants who failed to provide at least $75 \%$ of complete data on variables of interest.

In order to assess the degree to which the CMNI-29 would be an appropriate measure of conformity to masculine norms for the women in this sample, we conducted a confirmatory factor analysis (CFA) with maximum likelihood estimation 
in Mplus. CFA was used because it verifies the factor structure, or the number of factors, as well as the pattern of item-factor relationships, or factor loadings of the items in a specific sample (Brown, 2012). The latent factors were examined based on Hsu and Iwamoto's (2014) 8-factor, 29-item version of the CMNI, which demonstrated excellent overall model fit. The $\chi^{2}$ statistics with degrees of freedom and significance level, comparative fit index (CFI; Worthington \& Whittaker, 2006), the root mean square error of approximation (RMSEA), and the standardized rootmean-square residual (SRMR) were also examined. With regard to cutoff criteria, $\mathrm{Hu}$ and Bentler (1999) proposed criteria including an RMSEA value at or less than .05 for close model fit, SRMR less than .10, and CFI and TLI values of .95 or greater. As there are mixed findings with regard to which indices are best for evaluating model fit, and because indices can be impacted by a number of factors including sample size, it is noted that these cutoff criteria are general guidelines rather than definitive rules (Marsh, Balla, \& Hau, 1996; Worthington \& Whittaker, 2006), and researchers have applied less stringent cutoff criteria for evaluating model fit, with CFI and TLI values of greater .90 and an RMSEA value of less than .10 (Hopwood \& Donnellan, 2010; Perry, Nicholls, Clough, \& Crust, 2015).

For our primary analysis, negative binomial regressions were performed given that the outcome variables were count variables and the value distributions were skewed and overdispersed. This data analytic approach is common for alcohol outcomes because of the skewed nature of the outcomes (Neal \& Simmons, 2007). Next, in order to determine which specific feminine and masculine norms were significantly associated with the outcome variables, the variables were entered 
simultaneously for the two models: HED and the alcohol-related problems. Both models included the nine subscales from the CFNI-45 and the eight subscales from the CMNI-29, as well as the control variables (sorority status and perceived peer norms). We examined the incidence rate ratios (IRR's), which are exponentiated regression coefficients similar to an odds ratio. IRRs allow for an incremental interpretation of the outcome; for instance, if the IRR were 1.10, then the interpretation would be that for every one-unit increase in a specific predictor variable, there is a $10 \%$ increase in the outcome variable. Likewise, if the IRR were .90 , the interpretation would be that for every one-unit increase in the predictor variable, there is a $10 \%$ decrease in the outcome variable. 


\section{Chapter 3: Results}

The results of the CFA demonstrated acceptable model fit of the 8-factor structure of the CMNI-29 (Hsu \& Iwamoto, 2014) among this sample of women: $\chi^{2}$ $(N=624)=730.83, p<.001 ; \mathrm{RMSEA}=.04,90 \% \mathrm{CI}=.038, .046 ; \mathrm{SRMR}=.04 ; \mathrm{CFI}$ $=.94 ; \mathrm{TLI}=.93$. Given the acceptable model fit, we proceeded with the negative binomial regression to investigate the association between masculine, feminine norms, and the alcohol outcomes.

Descriptive statistics. Prior to the regression analysis, the distribution of the outcome variables HED and alcohol-related problems, was inspected. The results showed the values were skewed $($ HED skewness $=7.29$, alcohol-related skewness $=$ 1.05) and overdispersed, meaning the variance was significantly greater than the mean. The variance for alcohol-related problems was 24.05, and the mean was 4.98, while the variance for HED was 176.7 , and the mean was 7.44. This type of skewed distribution is common for self-reported alcohol outcomes, especially for count variables (Neal \& Simons, 2007). This type of skewed distribution indicates that the majority of women were engaging in HED or experiencing alcohol-related problems few or no times, whereas fewer women were engaging in HED and experiencing alcohol-related problems more frequently. In this sample, woman on average engaged in HED 7.44 times $(S D=13.33)$, while reporting an average of 4.98 alcohol-related problems $(S D=4.93)$ over the last three months. With regard to individual episodes of HED $65.7 \%$ of the women reported one or more episodes in the past three months, while $73.8 \%$ reported one or more alcohol-related problems experienced in the last three months. 
Heavy episodic drinking. This model examined how conformity to distinct masculine and feminine norms correlated with heavy episode drinking, and we hypothesized that masculine norms including risk-taking, playboy, and power over women, would be related to an increase in this outcome variable, while the norms self-reliance, heterosexual presentation, and emotional control, would be related to a decrease in the outcome variable. It was also hypothesized that the feminine norms modesty and sexuality fidelity would be related to a decrease in the outcome variable, while the feminine norms of thinness and appearance would be related to an increase in the outcome variable. The first model included HED as its outcome, while controlling for perceived peer norms for both men $(\operatorname{IRR}<1.12, p<.001)$ and women, and sorority status $(\operatorname{IRR}=1.90, p<.001)$. The results of the negative binomial regression revealed the masculine norms risk-taking, emotional control, and power over women were significantly associated with HED; specifically, risk-taking $(I R R=$ $1.11, p<.05)$ and emotional control $(I R R=1.07, p<.05)$ were associated with increased HED, whereas the norm power over women $(\operatorname{IRR}=.89, p<.01)$ was associated with a slight decrease in HED. The feminine norms significantly associated with HED were modesty, relational, and sexual fidelity norms; the norms modesty $(I R R=.93, p<.05)$ and sexual fidelity $(I R R=.86, p<.001)$ were associated with decreased HED, whereas the relational norm $(I R R=1.06, p<.05)$ was positively associated with HED. All results from this model are reported in Table 2.

Alcohol-related problems. The second model examined factors associated with alcohol-related problems, the control variables sorority status $(I R R=4.57, p<$ $.001)$ and perceived peer norms for both men $(I R R=1.12, p<.01)$ and women. 
Similar to the model above, it was hypothesized that distinct masculine or feminine norms would be related to increases or decreases in this outcome variable.

Subsequently, results indicated that the masculine norm risk-taking $(I R R=1.65, p<$ .001) was positively associated to alcohol-related problems. The feminine norms thinness $(I R R=1.20, p<.01)$ and appearance $(I R R=1.16, p<.01)$ were positively associated with alcohol-related problems, whereas the feminine norm sexual fidelity $(I R R=.70, p<.001)$ was negatively associated with alcohol-related problems. The results of the negative binomial regression model are reported in Table 2. 


\section{Chapter 4: Discussion}

The current study sought to advance the literature by examining masculine and feminine gender norm conformity in relation to heavy episodic drinking and alcohol-related problems among underage college women. The majority of underage women in this sample, approximately $66 \%$, engaged in at least one episode of heavy episodic drinking and approximately $74 \%$ reported at least one alcohol-related problem in the past three months. Accordingly, we examined how distinct gender norms were significantly associated with problematic drinking and related consequences among this at-risk population.

Among this sample, perceived peer norms and sorority status were significantly associated with HED and alcohol-related problems. These findings are consistent with previous research indicating that individuals who are involved with Greek sorority life, as well as individuals who perceive their peers to be drinking more, are at greater risk for engaging in heavy alcohol use themselves (Borsari, Murphy, \& Barnett, 2007; Capone, Wood, Borsari, \& Laird, 2007). Studies have consistently noted the relationship between Greek life and heavy drinking, reporting that members of sororities and fraternities report heavier drinking than non-members, perhaps because the social environment within the Greek system facilitates heavy drinking among its members (Sher, Bartholow, \& Nanda, 2001), and because drinking and partying are importance aspects of membership (Wechsler, Kuh, \& Davenport, 2009). Greek involvement is also predictive of increases in alcohol use and alcohol-related problems during the first few years of college, not only because of social influences, but also because of social modeling and availability of alcohol 
(Capone, Wood, Borsari, \& Laird, 2007), as well as peer perception of alcohol use and acceptability of heavy drinking (Larimer, Turner, Mallett, \& Geisner, 2004). One recent study noted that almost all members of Greek life drink, finding that across universities, approximately half of all sorority house residents were frequent binge drinkers (Wechsler, Kuh, \& Davenport, 2009). Thus, the finding that sorority status was significantly associated with both increased HED and alcohol-related consequences is not surprising. Additionally, perceived male peer norms were significantly associated with heavy episodic drinking and alcohol-related problems, while perceived female peer norms were not. This may be because women who perceive their male peers to be drinking in high quantities may subsequently be engaging in heavier alcohol use to impress those peers, to "keep up" with them, and to appear more attractive to them (Young et al., 2005). However, distinct masculine and feminine norms were significantly associated with HED and alcohol-related problems, even after controlling for these well-established determinants of alcohol use.

Results indicated the masculine norms risk-taking and emotional control were positively associated with HED, whereas the norm power over women was inversely related to HED in this sample. The norm power over women reflects endorsement of stereotypically masculine attitudes wherein men are "in charge," and exhibit dominance over women (Mahalik et al., 2003). Perhaps women who endorse this norm endorse more traditional notions of gender, and find these attitudes incompatible with drinking, and are thus less likely to consume alcohol. Previous studies have noted that women who endorse traditional feminine norms and attitudes 
may not engage in heavy drinking because it is an activity that is incompatible with traditional notions of femininity (Ricciardelli, Connor, Williams, \& Young, 2001). Alternatively, research has noted that women's increased empowerment and independence have been linked to increased alcohol use (Hutton, 2004). Thus, it may be true that for women who feel disempowered, such that they subscribe to the belief that men should wield power over women, the opposite is true for them. That is, these women are drinking less frequently, or perhaps women who do not endorse this norm are indeed associating heavy drinking with empowerment, and are drinking more frequently.

Furthermore, the finding that the masculine norm risk-taking is positively associated with HED is consistent with prior research among samples of men (Iwamoto et al., 2011). Indeed, it has been noted that the masculine norm of risktaking in particular is associated with a number of negative outcomes including excessive alcohol use (Liu \& Iwamoto, 2007), as both risk-taking and alcohol use reflect traditional, hegemonic notions of masculinity (Mahalik et al., 2003). Perhaps women who strive to move away from traditional notions of femininity by instead endorsing notions of masculinity, may value risk-taking as a reflection of masculinity, which in turn confers risk for heavier drinking. The result regarding the association between endorsement of risk-taking and increased HED is also theoretically consistent given that adherence of the risk-taking norm is conceptually similar to sensation-seeking and impulsivity (Mahalik et al., 2003). Women who conform to this norm may be more impulsive, which is a personality trait that has been associated with heavy drinking (see Verdejo-Garcia, Lawrence, \& Clarke, 2008 for a review). 
Research has also noted that heavy alcohol consumption may trigger impulsive behavior (Marczinski et al., 2005), therefore women who endorse risk-taking may engage in HED as a way of facilitating their risky behaviors. Future studies should include risk-taking masculine norms, as well as personality factors including impulsivity and sensation-seeking, to disentangle and clarify these relationships.

However, the finding that the norm emotional control is positively associated with HED is surprising and inconsistent with findings from samples of men, which have noted that the emotional control norm is inversely correlated with HED among men (Iwamoto et al., 2011). As Steinfeldt and colleagues (2011) note that gender norms may function differently across genders and contexts, possibly explaining why this norm is differentially related to a positive or negative outcome for men and women. Perhaps men who endorse the emotional control norm may avoid heavy drinking, as it would be too disinhibiting (Iwamoto et al., 2014), whereas women who endorse this norm may cope with their emotional repression through heavy drinking. Women who engage in heavy drinking may also endorse emotional control as a way to "fit in" and prove themselves to their peers (Young et al., 2005). While theses hypotheses are speculative, these findings highlight the importance of understanding how distinct masculine norms may help explain drinking patterns of women who are under the legal drinking age.

In addition to distinct masculine norms explaining unique variance in HED, the feminine norms modesty and sexual fidelity were associated with decreased HED. These findings are consistent with previous research on feminine norms and drinking (Ricciardelli, Connor, Williams, \& Young, 2001). The sexual fidelity norm was 
robustly associated with HED, such that the women in this sample who endorsed this norm were less likely to engage in HED. This norm refers to the notion that women should only engage in sexual activity within a monogamous relationship (Mahalik et al., 2005). Given that the sexual fidelity norm is reflective of traditional attitudes, perhaps women who endorse this norm may feel that excessive alcohol consumption may jeopardize their romantic relationships, and are thus less likely to engage in HED (Simonen, 2013). Moreover women who endorse the sexual fidelity norm do not feel the need to engage in HED to facilitate their social interactions with men (Young et al., 2005). However, the feminine norm relational, or being invested in personal relationships, was positively associated with HED. This may be because women who value their social relationships may desire to drink more frequently in social situations, or may have difficulty refusing to drink when invited to drink in a social setting. Furthermore, alcohol is perceived as a "social lubricant," and women who value their personal relationships may drink larger quantities to facilitate these relationships (Labrie et al., 2009).

For the outcome alcohol-related problems, the masculine norm risk-taking was significantly associated with increased alcohol-related problems. This is consistent with previous studies focusing on masculine norms among men (Iwamoto et al., 2011), and may indicate that women who enjoy taking risks are more likely to drink problematically, and thus experience more frequent alcohol-related problems. Furthermore, in this sample, the risk-taking norm was associated with increased HED, therefore women who endorse this norm may be drinking more and subsequently experiencing more consequences as a result. The feminine norm sexual fidelity was 
negatively associated with alcohol-related problems, perhaps because it is also significantly related with decreased drinking overall. That is, women who endorse this norm may be less likely to drink, and thus are less likely to experience the negative consequences associated with drinking.

There were also a few feminine norms associated with increased alcoholrelated problems, including thinness and appearance. This is consistent with previous research examining women's drinking patterns, as this research has noted that women who appear to value their appearance may be drinking more problematically (Young et al., 2005). The link between women who are invested in their appearance and physique may be attributable to women's gender socialization (Parks, Miller, Collins, \& Zetes-Zanatta, 1998). That is, women's drinking behavior may be self-validating, and women who are socialized to drink in order to appear more attractive to male peers, may be drinking more problematically (Iwamoto et al., 2015; Young et al., 2005). Perhaps women who endorse appearance and thinness norms may be more susceptible to peer influences and peer pressure in general, and may have a harder time refusing to drink, or may drink excessively as a result of social pressures. The hypotheses described above are tentative and must be explored further. Accordingly, there are several limitations that must be taken into consideration.

\section{Limitations and Implications for Research and Practice}

Factors that may threaten the external validity of the study include the college's geographic location, as well as its sociopolitical environment and drinking culture. Social and political attitudes regarding drinking may differ from one location to another, thus the results from this study might not be generalizable. Furthermore, 
the data collected for this particular sample were cross-sectional, thus causal relations between the specific gender norms and alcohol outcomes cannot be inferred. The questionnaire that was used for data analysis also did not include validity checks throughout the question sets. In order to determine whether a participant appeared to have thoughtfully completed the survey, we were able to check timestamps to determine approximately how much time a participant spent on answering the questions. However, this may not have guaranteed that all participants included in the final analysis were carefully answering the questions, which may have implications for our findings.

Additionally, there has been controversy regarding the validity of selfreported alcohol use (Midanik, 1988), which warrants a discussion given that in this study, participants reported their frequency of HED over the past three months. Our measure of HED was influenced by the Alcohol Timeline Followback, which asks participants to retrospectively estimate their drinking within a specific time frame, and is the preferred measurement when a relatively precise estimate of drinking, or frequency of drinking at a specific level, is needed (Sobell \& Sobell, 1995). Specifically, this study used a single-item measure to assess HED, and it has been noted that single-item self-report measures are reliable measures of alcohol use, and may in fact be a good method of measurement given its brevity, which maximizes participants' response rates (Dollinger \& Malmquist, 2009). Furthermore, participants may feel more comfortable reporting their alcohol use in online measures (Pedersen et al., 2012), and there has also been extensive research indicating that adolescents' and young adults' responses to self-report measures of alcohol use are both reliable 
and valid (Smith, McCarthy, \& Goldman, 1995). While there is no guarantee that all of the participants' self-reported alcohol data were accurate, research has noted that alcohol self-report measures are generally reliable and valid. Finally, another potential limitation was the use of the CMNI-29 (Hsu \& Iwamoto, 2014) among a sample of women. Although our confirmatory factor analysis showed acceptable model fit, indicating that women were responding to the masculine norm inventory items such that the items were loading well onto their respective factors, it is possible that women interpreted certain items on this inventory differently than men. Therefore, women's responses to this measure may not conceptually capture masculine norm endorsement as it would for men. For instance, the norm "power over women," while presented in a way so as not to make it obvious the question was designed for men, may still have been interpreted or internalized differently among women. Whereas for men, the norm conceptually measures gender-based dominance of women, women who endorse the "power over women" norm may have internalized misogyny or male oppression, rather than wishing to perpetuate this oppression themselves. Another example is in the "playboy" norm, which denotes wishing to have multiple sexual partners; for men, this norm is related to hegemonic or dominant masculinity, whereas for women, it may be related to a more egalitarian view given societal restrictions of women's sexuality and expectations of monogamy (Young et al., 2005). Given men and women's unique gender socialization, the items on this inventory may have been interpreted differently and may not have captured the intended norms. 
Despite these limitations, these findings may have significant clinical and prevention implications. Previous studies have demonstrated that endorsement of various masculine and feminine norms can be positively or negatively associated with HED and alcohol-related problems (Iwamoto et al., 2011), even when controlling for well-established determinants of alcohol use. This illustrates the importance of examining gender norms, as gender norms explain alcohol use beyond other wellestablished predictors of alcohol use. Feminine and masculine norms could be assessed in a clinical setting, and prevention efforts focused on alcohol use could attempt to increase awareness around the impact of gender norm endorsement on HED and alcohol-related problems. It may be fruitful for clinicians to explore with their female clients the meaning of these feminine and masculine norms, as well as their costs and benefits, and how endorsing these norms might influence their health behaviors, including problematic alcohol use. One significant point of intervention may be targeted toward women who are involved in Greek life, as this was significantly associated with both increased HED and alcohol-related problems. It may be beneficial to help at-risk women consider the role of sorority peer norms, as well as their constructions of femininity, in influencing their problematic alcohol use, as well as to challenge the notion that women must "keep up" with men in drinking in order to be more attractive or appealing (Young et al., 2005).

It has been noted that gender norms are socially constructed, dynamic, and vary across contexts, rather than being biologically driven or inherent (Mahalik et al., 2003). Just as individuals learn and internalize gender norms, they can also question and reject them, particularly those norms that predispose people to negative health 
outcomes or risky behaviors (Barker et al., 2010). Accordingly, clinicians may be able to help female clients consider how their gender norm endorsement affects their health, or even incorporate a gender-transformative approach within therapy. Indeed, research has pointed to the efficacy of gender-specific interventions in changing health-related behaviors and outcomes (Barker et al., 2010). Emerging research suggests that gender-based interventions that challenge norms which induce negative health outcomes, can be both efficacious and avoid reinforcement of harmful hegemonic gender norms (see Fleming, Lee, \& Dworkin, 2014 for a review). Future studies may consider developing gender-specific interventions to address problematic alcohol use on college campuses, as well as address their efficacy over other types of interventions. Specifically, these interventions could challenge gender norms that correlate with increased risk of HED and alcohol-related problems, while encouraging young women to think critically about their motivations for consuming alcohol.

The present study sought to understand how both masculine and feminine norms may influence underage women's drinking behaviors and outcomes. To our knowledge, this is the first study to examine both masculine and feminine norms in relation to alcohol use among a sample of U.S. young adult women who are under the legal drinking age. This study contributes to the literature in that we examined both feminine and masculine norms among a group of women, whereas previous studies examining gender norm conformity have largely looked at feminine norm endorsement for women (Parent \& Smiler, 2013). Through this research, we were 
able to identify how both feminine and masculine norms may help explain heavy episodic drinking and alcohol-related problems among underage women. 


\section{Appendices}

Table 1: Model results of negative binomial regression

\begin{tabular}{|c|c|c|c|c|c|c|}
\hline \multicolumn{5}{|c|}{ Heavy episodic drinking } & \multicolumn{2}{|c|}{ Alcohol-related problems } \\
\hline Variable & $\beta$ & $\mathrm{SE}$ & IRR & $\beta$ & SE & IRR \\
\hline \multicolumn{7}{|l|}{ Feminine norms } \\
\hline Thin & .02 & .02 & 1.02 & $.18^{* *}$ & .05 & 1.20 \\
\hline Domestic & -.02 & .03 & .98 & -.09 & .06 & .91 \\
\hline Appear & -.01 & .02 & 1.01 & $.15^{* *}$ & .05 & 1.16 \\
\hline Modesty & $-.07^{*}$ & .03 & .93 & -.10 & .09 & .90 \\
\hline Relational & $.06^{*}$ & .03 & 1.06 & .10 & .08 & 1.11 \\
\hline Child & -.02 & .02 & .98 & -.01 & .06 & .99 \\
\hline Sex & $-.15^{* *}$ & .02 & .86 & $-.35^{* *}$ & .06 & .70 \\
\hline Romantic & .00 & .02 & 1.00 & .11 & .06 & 1.12 \\
\hline Sweet & .00 & .03 & 1.00 & .02 & .09 & 1.09 \\
\hline \multicolumn{7}{|l|}{$\begin{array}{l}\text { Masculine } \\
\text { norms }\end{array}$} \\
\hline Winning & -.03 & .03 & .97 & -.02 & .09 & .98 \\
\hline Playboy & -.01 & .05 & .99 & .00 & .14 & 1.00 \\
\hline Self-R & .05 & .03 & 1.05 & .15 & .09 & 1.16 \\
\hline Violence & -.02 & .03 & .98 & .01 & .07 & 1.01 \\
\hline HP & .03 & .02 & 1.03 & .06 & .05 & 1.06 \\
\hline Risk & $.10^{* *}$ & .04 & 1.11 & $.50^{* *}$ & .12 & 1.65 \\
\hline Emotion & $.07^{*}$ & .03 & 1.07 & .07 & .10 & 1.07 \\
\hline Power & $-.11^{* *}$ & .04 & .89 & .14 & .13 & 1.15 \\
\hline \multicolumn{7}{|l|}{$\begin{array}{l}\text { Control } \\
\text { variables }\end{array}$} \\
\hline Sorority & $.64^{* *}$ & .13 & 1.90 & $1.52^{* * *}$ & .41 & 4.57 \\
\hline Peer (M) & $.05^{* *}$ & .01 & 1.05 & $.11^{* *}$ & .04 & 1.12 \\
\hline Peer (F) & -.02 & .02 & .98 & -.07 & .05 & .93 \\
\hline \multicolumn{7}{|c|}{$\begin{array}{l}\text { IRR }=\text { incidence rate ratio, } \text { Thin }=\text { thinness, } \text { Appear }=\text { invest in appearance, } \text { Romantic }= \\
\text { romantic relationship, Sweet }=\text { sweet and nice, } \text { Child }=\text { care for children, Self- } R=\text { self- } \\
\text { reliance, } H P=\text { heterosexual presentation, } \text { Risk }=\text { risk-taking, Emotion }=\text { emotional control, } \\
\text { Peer }=\text { perceived peer norms male and female. } \\
* p<.05 ; * *<<.01\end{array}$} \\
\hline
\end{tabular}




\section{Appendix A}

\section{Review of Literature}

The literature review is presented in three sections: gender norms, alcohol use, and the intersection of gender norms and alcohol use. This review first describes the constructs of feminine and masculine norms in greater detail, examining measures of gender norms as both unidimensional and multidimensional, as well as how they have been associated with health outcomes in general. The next portion of the review focuses on alcohol use and alcohol-related problems and consequences as significant public health concerns, and the last section discusses how these alcohol outcomes are related to gender constructs.

\section{Independent Variables: Masculine and Feminine Norms}

Social norms guide and constrain individuals' behaviors, as they teach people what is expected of them in social interactions. Likewise, gender norms are rules and standards that guide and constrain masculine and feminine behaviors, such that they teach men and women acceptable and unacceptable behaviors associated with their gender (Mahalik et al., 2003). Gender norms, in addition to providing guidance for behaviors and thoughts, are also a significant part of men and women's identity development (Mahalik et al., 2005). Thus, researchers have studied gender in order to explain men and women's behaviors in a variety of domains, including health-related practices such as alcohol use.

\section{Gender as Unidimensional}

Gender has long been studied as a unidimensional construct, with the most commonly used measures of gender being the Bem Sex Role Inventory (BSRI; Bem, 
1974) and the Personal Attributes Questionnaire (PAQ; Spence \& Helmreich, 1978). The BSRI reflects the notion that masculinity and femininity are antithetical, and measures the single attributes of masculinity and femininity as existing on a continuum, while also yielding a score on androgyny (Bem, 1974). The PAQ similarly scores individuals as being high or low on masculinity or femininity, and has found that, congruent with stereotypes, men tend to score higher on instrumentality, and women tend to score higher on expressive femininity (Spence \& Helmreich, 1979). Both measures capture traditional notions of gender, which have essentially reduced masculinity to a concept of agency, or sense of self, and femininity to communion, or sense of selflessness (Gilbert, 1981). Within this unidimensional understanding of gender, those who identify with stereotypical masculinity are self-reliant, assertive, and ambitious, while those who strive for stereotypical femininity are expressive, compassionate, and sensitive to others' needs (Strough, Leszcynski, Neely, Flinn, \& Margrett, 2007).

These measures were introduced before the gender ideology approach, which suggested that masculinity and femininity were multidimensional in nature (Smiler 2004; 2010). While useful, unidimensional measures may not fully capture gendered expectations and norms, or nuances in how individuals express their gender, given that they only gauge the degree of femininity or masculinity an individual possesses, rather than which specific masculine or feminine traits an individual may have. Furthermore, gender norms are influenced by a number of cultural ideologies that cannot be captured within a global measure (Mahalik et al., 2005). That is, expressions of masculinity and femininity include more than agency or selflessness, 
and the way in which individuals express their gender changes based on time, context, and social expectations.

\section{Gender as Multidimensional}

Contrarily to a unidimensional approach, a multidimensional approach to gender does not measure whether someone is feminine or masculine, but rather to what extent an individual endorses specific feminine or masculine norms, as well as which norms are most salient to an individual. This posits that people may endorse some gender norms for their given gender, but not others. For instance, some women might strongly endorse the traditional feminine norm of being nurturing, while others may place greater significance in norms of being thin and beautiful (Mahalik et al., 2005). Accordingly, contemporary research has been shifting toward a multidimensional model of gender-relevant factors.

One theoretically sound conceptualization of gender includes adherence to specific gender norms, wherein individuals are not intrinsically masculine or feminine, but rather practice masculinity and femininity through endorsement of gender norms (Lyons, 2009). These feminine and masculine norms reflect expectations and beliefs about what it means to be a man or a woman in contemporary U.S. society, and embody hegemonic performances of gender such that they are linked to a heterosexual, White, and middle class status (Schippers, 2007). Gender norms are learned from an early age through social interactions; for example, boys learn from a young age that they should not like pink, should not play with dolls, and should not cry, whereas girls are taught to be considerate, expressive, and nurturing (Mahalik et al., 2003; 2005). Gender norms are also taught through other 
mediums including the media, and individuals are expected to comply with the norms of their respective gender identity. People adopt behaviors that display their gender, making behaviors a way of expressing one's gender identity (Woodhill \& Samuels, 2003).

Contemporary multidimensional measures of masculine and feminine norms include the Conformity to Masculine Norms Inventory (CMNI; Mahalik et al., 2003) and the Conformity to Feminine Norms Inventory (CFNI; Mahalik et al., 2005), and their shortened versions, the CMNI-46, CMNI-29, and the CNFI-45 (Hsu \& Iwamoto, 2014; Parent \& Moradi, 2009; 2010). Mahalik and his colleagues (2003; 2005) developed the CMNI and the CFNI to assess the extent to which men and women conform to gender norms that are reflective of dominant U.S. culture. This is posited because gender norms as established by the most dominant groups in society become the standards to which other groups must conform. That is, constructions of masculinity and femininity as they pertain to White, middle-class, and heterosexual men and women, are the standards of masculinity and femininity that other groups are taught to conform to (Mahalik et al., 2005).

Conformity to Masculine Norms. In order to create the CMNI, Mahalik et al. (2003) first identified masculine norms within dominant U.S. culture by reviewing the literature on traditional notions of masculinity. It is noted that the masculine norms had to be distinct from feminine norms, as there are separate gender schemas associated with masculinity and femininity (Bem, 1981). Next, the authors (Mahalik et al., 2003) conducted a series of focus groups among men and women, in order to refine the categories of the norms as well as to construct items to assess each norm on 
a continuum. This process yielded 12 distinct masculine norms, assessed with 94 items, which were then pilot tested before being distributed to a sample of 752 men. The mean age of this sample was 20 years old $(S D=3.42)$, and the vast majority was White, heterosexual, and either in college or graduate school. The factor analysis of the data indicated an 11-factor solution, which accounted for $42.6 \%$ of variance. The dimensions of masculine norms that emerged were: Winning, Emotional Control, Risk-taking, Violence, Power over Women, Dominance, Playboy, Self-reliance, Primacy of Work, Disdain for Homosexuals, and Pursuit of Status.

To further test the CMNI and obtain internal consistency estimates, Mahalik and colleagues (2003) conducted a separate study in which they administered the measure to 245 women, in addition to the 752 men from the first study. 450 participants within the male sample were also given "Yes" or "No" health-related questions including whether they had been involved in a violent situation in the last year, and at least once in their life drank so much that they blacked out, or could not remember what they had done while drinking. The internal consistency estimates were sound, ranging from .72 to .91 , with the total coefficient alpha being .94 .

As expected, results of a one-tailed $t$ test indicated men and women differed on their endorsement of masculine norms, with men scoring significantly higher than women on total conformity as well as on most of the norm scores including: Winning, Emotional Control, Risk-taking, Violence, Power over Women, Dominance, Playboy, Self-reliance, and Disdain for homosexuals, but not significantly higher on the norms Primacy of Work and Pursuit of Status. 
To obtain the results regarding health outcomes and masculine norms, the authors conducted a series of one-tailed $t$ tests. Results indicated that men who answered "yes" to whether they had been involved in a violent situation scored significantly higher on the norms of Winning, Risk-Taking, Violence, Power over Women, Dominance, Playboy, Disdain for Homosexuals, and their total CMNI score. The men who answered "yes" pertaining to whether they had drank so much they forgot what they were doing, scored significantly higher on Risk-Taking, Violence, Playboy, and the total CMNI score.

These results had several significant implications; first, men and women differ on overall conformity to masculine norms, and there are specific masculine norms that are significantly associated with health-impacting behaviors including drinking and violent behaviors. This is in line with prior research indicating that men who engage in high-risk behaviors are driven to do so by masculine role expectations (Mahalik et al., 2003). While research has long acknowledged that striving for masculinity is associated with high-risk behaviors, the study detailed above demonstrates that specific masculine norms, particularly those pertaining to risktaking, are particularly useful for predicting men's engagement with a variety of health-risking behaviors.

In order to advance the use of the CMNI, Parent and Moradi (2009) conducted the first factor analysis of the CMNI since its creation, and then developed an abbreviated version of it, the CMNI-46. While the factor analysis of the CMNI supported nine of the eleven factors, it also suggested removing two factors, Dominance and Pursuit of Status, given low factor loadings and weak reliability 
coefficients. The confirmatory factor analysis, using maximum likelihood estimation, was conducted among a sample of 229 undergraduate men, whose mean age was $19.95(S D=3.23)$. The majority of the men were White $(59 \%)$ or Asian/Asian American (23\%). Shortening the measure into the CMNI-46 resulted in acceptable data-model fit on all fit indices, $\chi^{2}(953, N=229)=1414.30, p<.001$; RMSEA $=$ $.046,90 \% \mathrm{CI}=.041, .051 ; \mathrm{SRMR}=.0591 ; \mathrm{CFI}=.90$. The CFA provides support for the multidimensional nature of the CMNI, as proposed by Mahalik et al. (2003), and also supported a 9-factor structure, as opposed to the previous 11 factor structure. Most importantly, the CMNI-46 retains the conceptual properties of the original CMNI, with less than half the items, while still retaining its multidimensional structure.

To further streamline the measure on conformity to masculine norms, Hsu \& Iwamoto (2014) developed the CMNI-29, which was used in the present study. Participants consisted of 893 men, of whom most were Asian Americans $(N=681)$, and White Americans $(N=212)$, with the average age being $20.41(S D=2.34)$. Notably, this measure was developed after testing for measurement invariance in the CMNI-46 among White and Asian American men, and determining that the CMNI-46 is more theoretically consistent for White men. This finding is not surprising, given that the CMNI was developed to reflect hegemonic masculinity, that is, masculinity pertaining to White men (Mahalik et al., 2003). The CMNI-29 was developed through exploratory and multigroup confirmatory factor analysis, yielding an 8-factor structure and demonstrating excellent overall model fit for both White and Asian American men, $\chi^{2}(349, N=893)=965.26, p<.001 ; \mathrm{RMSEA}=.04,90 \% \mathrm{CI}=.041$, 
.048 ; SRMR $=.04 ; \mathrm{CFI}=.93$. The 8 factors in the CMNI-29 are Winning, Playboy, Self-Reliance, Violence, Heterosexual Presentation, Risk Taking, Emotional Control, and Power over Women.

Measuring masculine norms in women. Recently, the CMNI-46 (Parent \& Moradi, 2009) has been examined in order to determine whether it is an appropriate measure of endorsement of masculine norms among women. Parent and Smiler (2013) addressed this, guided by theory stating that both men and women can endorse masculinity (Bem, 1974), and noted that masculine gender norm conformity might be important for women as well as for men. This is not only because masculinity is not exclusive to just men, but also because there is a lack of understanding regarding the implications of women's adherence to masculine norms (Parent \& Smiler, 2013). Given that endorsement of masculine norms has been linked to a myriad of health problems, including alcohol use, drug use, and unsafe sex (Parent, Moradi, Rummell, \& Tokar, 2011), among samples of men, this may indicate that women who endorse masculine norms may also show similar patterns of engaging in risky behaviors.

In order to determine whether the CMNI-46 adequately measures masculine norm endorsement among women, one study examined measurement invariance of the measure's factor structure in a sample of men and women (Parent \& Smiler, 2013). They explored three aspects of invariance: configural invariance, which assesses the measure's factor structure across groups and assesses whether the scale can be used for both; metric invariance, which examines whether a scale measures the same constructs across groups, and finally, scalar invariance, which compares means across groups. This is done through structural equation modeling, in which the 
models of invariance are tested simultaneously across groups. Nonsignificant changes in the $\chi^{2}$ statistic, a change in the comparative fit index (CFI) less than .010, and change in the root mean square error of approximation (RMSEA) less than .015, indicate invariance support. The sample included 335 men and 330 men with a mean age of $30.51(S D=15.15)$, and a majority of the sample was White. The participants were administered both the original 94-item CMNI (Mahalik et al., 2003), and the abbreviated CMNI-46. The authors first tested for configural invariance, and found that the SRMR and RMSEA values were acceptable, but the CFI fell below recommended cutoffs - however, they concluded that configural invariance was met, indicating that the CMNI-46 reflects similar constructs within samples of both men and women. The model also passed metric invariance, again indicating that the items on the measures reflect the same constructs among men and women. Finally, the model did not pass scalar invariance, indicated that women had lower intercepts across the measures in comparison to men. Subsequently, the authors concluded that while the measure adequately captures the abstract notion of masculinity among both men and women, and is thus psychometrically valid among samples of women, men and women differed significantly in their endorsement of masculine norms. That is, the construct of masculine functions in the same way for men and women, but women's adherence to masculine norms differs from men's adherence. However, it is noted that the study did not address how men and women interpret the items (Parent \& Smiler, 2013).

In line with theory that women can adhere to masculine norms, Steinfeldt and colleagues (2011) studied conformity to masculine norms among female athletes, 
arguing that through playing sports, women are exposed to a traditionally masculine domain and thus may endorse greater masculinity. The authors were particularly interested in studying body image and body esteem, arguing that female athletes may have greater concern about body image, as they are often dressed in revealing uniforms and placed in front of spectators. Thus, it was expected that certain gender norms would affect female athletes more than they would other women, and that female athletes would have less conformity to feminine norms and greater conformity to masculine norms. Steinfeldt and colleagues (2011) recruited 143 female college students, who played in a variety of sports, and whose mean age was $19.74(S D=$ 1.31). Half of the participants reported being dissatisfied with their bodies, and of these, $44 \%$ felt that they were overweight, while $6 \%$ felt that they were underweight, and the average BMI of the sample was $23.73(S D=3.51)$. The participants were given both the CFNI-45 (Parent \& Moradi, 2010) and the CMNI-46 (Parent \& Moradi, 2009), as well as a scale on body esteem. Two Multivariate Analysis of Variance (MANOVAs) were conducted to test endorsement of gender norms, and to test the hypotheses that female athletes would have less endorsement of feminine norms and greater endorsement of masculine norms. However, the findings were mixed, indicating that while there were no differences in endorsement of feminine norms - that is, female athletes did not differ significantly in endorsement of feminine norms as compared to non-athletes - the athletes did somewhat differ on endorsement of masculine norms, with higher endorsement of Risk-taking and Winning norms. These results indicate that female athletes conform to traditional masculine norms that are associated with participation in sports. In relation to the outcomes of body 
esteem, the authors note that although the masculine norm Risk-taking has been associated with negative outcomes including higher levels of alcohol use (Liu \& Iwamoto, 2007), this norm was linked to a positive outcome - higher levels of body esteem - among the women in this sample. This may indicate how masculine norms operate differently for women in certain domains such as sports.

Conformity to Feminine Norms. Mahalik and colleagues (2005) developed the conformity to feminine norms inventory (CFNI), on the basis that global measures of femininity, such as the Bem Sex Role Inventory and MMPI-2 Feminine Gender Role Scale, largely conflate femininity with instrumentality, rather than attempting to differentiate among the different cultural and social constructions of femininity. It is noted that gender roles are instead comprised of a large number of cultural ideologies, and that women experience a number of sociocultural expectations that define femininity, such as being nurturing, physically attractive, submissive, and so on (Mahalik et al., 2005). Accordingly, the CFNI attempts to measure the salience of a number of feminine norms for individual women, as women construct their femininity based on the norms that are most salient for them. Thus, in order to fully understand how different facets of femininity affect individual women, researchers must measure these different facets and to what extent they are endorsed. Similarly to the CMNI, Mahalik and colleagues (2005) created the items on the CFNI to measure adherence to feminine norms that reflect dominant U.S. cultural norms, such that they are based on White, middle-class, and heterosexual status, because feminine ideologies that reflect dominant European American culture are considered the most powerful and salient in U.S. society (Mahalik et al., 2003). 
To create the items on the CFNI, the authors reviewed literature on feminine norms in dominant U.S. culture, then conducted focus groups among five groups of 32 women, made up of predominantly European American and heterosexual women. The most salient feminine norms that were identified included: "Self as mother," "be relational-connected," "be silent," "be dependent," "be physically attractiveornamental," "defer to men," "be virginal," and "be sexy." Based on these and other themes that were presented in the focus groups, the feminine norms survey was refined into 12 categories that included Relational, Sweet and Nice, Thinness, Put Others First, Look Young, Sexy, Modesty, Domestic, and Caring for Children. This created a survey of 144 items, which was then analyzed to identify the factor structure.

First, the authors examined the factor structure of the CFNI through exploratory factor analysis, beginning with 12 factors. The factor analysis determined that a 10-factor solution, however, was the strongest. The final factor solution consisted of 118 items and 8 subscales that accounted for $39.51 \%$ of the variance, and after dropping the items with factor loadings of lower than .4, the final scale retained 84 items with 8 factors. These factors are: Nice in Relationships or developing friendly and supportive relationships with others, Thinness or pursuing a thin body ideal, Modesty or refraining from calling attention to one's talents and abilities, Domestic or maintaining the home, Care for Children or taking care of and being with children, Romantic Relationship or investing self in a romantic relationship, Sexual Fidelity or keeping sexual intimacy contained within one committed relationship, and 
Invest in Appearance or committing resources to maintaining and improving physical appearance (Mahalik et al., 2005).

This 8-factor structure supports that notion that there are multiple feminine norms that are relevant for women, and that these norms are distinguishable from one another. Next, the authors conducted a study to examine the internal consistency estimates of the CFNI, to determine if CFNI scores differ for men and women - based on rationale that women would be more likely to conform to feminine norms than men, and finally to determine if CFNI scores related to constructs of global femininity, masculinity, and feminist identity development. In this portion of the study, the participants included the 733 women who were originally in the study, as well as 98 men. Of these participants, 211 women completed other measures of femininity such as the Bem Sex Role Inventory and the Feminine Identity Development Scale, with the average age of these women being $18.83(S D=.73)$. The internal consistency estimates were high, at about $\alpha=.88$ for the CFNI Total score, with the subscales ranging from .77 (Romantic Relationship) to .92 (Caring for Children). As expected, women generally endorsed feminine norms more than men, as indicated through one-tailed $t$-tests. Women scored significantly higher than men on the CFNI Total score, and on 6 of the 8 subscales (Nice in Relationships, Sexual Fidelity, Domestic, Invest in Appearance, Caring for Children, Thinness), but not on the norms Modesty and Romantic Relationship.

The shortened version of the CFNI, the CFNI-46 (Parent \& Moradi, 2010), was created to both re-evaluate the psychometric properties of the original CFNI, as well as to validate the factor structure and to create a shortened version. This was 
significant, given that the original version has 84 items, which may limit its use in research because the length could contribute to participant fatigue. Analyses were conducted using data from 243 female undergraduate students, whose ages ranged from 18 to $49(M=20.12, S D=4.43) .70 \%$ of this sample was White, while about $20 \%$ was Asian/Asian American, and 91\% was heterosexual. To examine the factor structure, the authors conducted confirmatory factor analysis using maximum likelihood estimation. The CFA supported a 9-factor model, as the subscale Nice in Relationships was split into two subscales, Relational and Sweet and Nice. Other factors were obtained based on how high the factor loadings were, and each subscale was limited to five items, yielding the 9-factor, 45 -item measure. The final measure retained the multidimensional factor structure of the original CFNI, but conceptually and empirically improved on the original, in addition to reducing the number of items.

It is posited that feminine norms play an important role in women's lives, and constrain and disempower women (Parent \& Moradi, 2010). Because feminine norms are so important, and affect a large number of domains in women's lives, it is important to accurately assess conformity to feminine norms, and then understand how these norms influence behaviors, attitudes, and practices. However, women may endorse norms outside of conventional femininity, particularly because feminine norms can be restrictive and disempowering. Instead, women may eschew traditional, restrictive norms and strive to act in more stereotypically masculine ways, as masculinity is associated with empowerment. Women are also increasingly entering social domains that have traditionally been male-dominated spaces, such as 
employment and public drinking areas, and may thus be acting in more masculine ways (Lyons \& Willott, 2008). Thus, it is important to understand not only how feminine norms influence women's behaviors, but also how masculine norms may influence them as well.

\section{Outcomes: Alcohol Use and Alcohol-related Problems}

Alcohol use has been increasing among college students. National surveys have focused on frequencies of binge drinking, which is defined as consuming five or more drinks in a two-hour sitting for men, and four or more drinks for women. In 1999, in a random sample of 14,138 students selected from 128 colleges and universities, $44 \%$ of these students reported at least one episode of binge drinking, or heavy episodic drinking, in the previous year (Hingson, Heeren, Winter, \& Wechsler, 2005). $23 \%$ of the students sampled engaged in even more frequent heavy episodic drinking, reporting having done this 3 or more times in the past 2 weeks. Results from this survey also indicated that the drinking rates had increased in the last five years, and that college students were drinking more frequently than same-age noncollege peers $(35 \%)$ and high school students $(31 \%)$. These increasing rates of alcohol use have significant consequences; for instance, coinciding with the increasing rates of binge drinking is an increase in the rate of alcohol-related deaths among 18-to-24 year old students, with an $11 \%$ increase from 1998 to 2001 in the U.S. Furthermore, it has been estimated that $33 \%$ of alcohol-related traffic fatalities consist of college students (Hingson et al., 2005). In the time frame of 1998 to 2001, total number of unintentional deaths that were alcohol-related increased by $12 \%$. While these numbers are concerning, it is noted that they do not include deaths related to 
homicides and suicides, many of which are also influenced by alcohol use (Hingson et al., 2005). Taken together, these findings demonstrate the significance of alcohol use as a public health concern.

Within the United States, drinking, including binge drinking, is more prevalent among men than women (Centers for Disease Control and Prevention, 2012). In 2012, the National Institute on Alcohol Abuse and Alcoholism found that $28.8 \%$ of women and $43.1 \%$ of men reported binge drinking in the previous year. Studies sampling drinking rates internationally have found similar results, indicating that cross-culturally, men drink at higher rates than women (Wilsnack et al., 2009; Rahav et al., 2006). Wilsnack and colleagues (2009) argue that women drink less frequently for a number of reasons, including: women generally are lighter drinkers than men, drinking is not as significant for women's social roles as it is for men's, and because women may stop drinking during pregnancy and child-rearing, and then may not resume drinking.

However, there have been recent reports of women's drinking rates increasing significantly, suggesting that the gender gap in alcohol use and dependence is narrowing (Grucza et al., 2008). Keyes, Grant, and Hasin (2008) noted that differences in men's and women's alcohol consumption and alcohol use disorders have decreased in birth cohorts reaching adulthood since the 1970s, in comparison to earlier birth cohorts. In order to test this, they aimed to study birth cohort effects in a nationally representative sample consisting of 42,693 adults under the age of 90 , whose birth cohorts were divided into four sets: 1913-1932, 1933-1949, 1950-1967, and 1968-1984. It was theorized that birth cohorts would have an effect on women's 
increasing drinking, given the change in traditional gender roles in the U.S. since the 1970s. This change is apparent in women's increasing presence in the workforce and decreasing proportions of having children. In line with these diminishing restrictive gender roles, women's drinking has become de-stigmatized, and women have been able to drink at similar rates as men. In the study on birth cohort effects, the authors examined data from the 2001-2002 National Epidemiologic Survey on Alcohol and Related Conditions (NESARC), a nationally representative sample of cross-sectional and qualitative data, with a response rate of $81 \%$. The majority of the sample was White (70.9\%), $47.6 \%$ was male; $21.8 \%$ of the sample was between the ages of 18 $29,30.9 \%$ were $30-44,31.1 \%$ were $45-64$, and $16.2 \%$ were 65 or older. While results indicated that men were more likely to have alcohol abuse than women, frequent binge drinking increased among women by birth cohort.

The narrowing gender gap in drinking is alarming for women in particular, given biological factors that make women more sensitive to adverse health effects due to heavy drinking. Furthermore, research has identified the "telescoping" effect, wherein women generally initiate drinking later than men but progress more quickly to alcohol dependence (Randall et al., 1999). Randall and colleagues (1999) explored this by gathering data over the course of a large clinical trial among 1,307 men and 419 women enrolled in an alcohol treatment study. Participants were recruited from outpatient and aftercare settings over the course of 2 years, and researchers collected data on gender differences in age-of-onset variables and progression times. The differences were tested with ANOVA, and the authors determined that women, on average, began drinking at a later age than men (26.6 versus 22.7 years, $p \leq .001)$, but 
progressed faster than men between first getting drunk regularly and encountering drinking problems ( 0.9 years versus 2.3 years, $p \leq .001)$, as well as to first loss of control after drinking and onset of severe drinking problems (5.5 years versus 7.8 years, $p \leq .001)$. However, consistent with theory stating that women generally are more help-seeking (Lyons, 2009), the study also found that women tended to seek treatment more quickly than men (11.6 years versus 15.8 years, $p \leq .001$ ), although this was true for older women, rather than younger women (Randall et al., 1999). There are a number of other health consequences related to alcohol use that are specific to women. For instance, breast cancer risk increases as drinking increases, and even moderate alcohol consumption increases risk (Wilsnack \& Wilsnack, 2014). And while the links are unclear, there is evidence suggesting that there is a link between women's drinking and a number of psychiatric disorders, including affective, anxiety, and somatoform, and that this connection between drinking and psychiatric disorders is stronger for women than for men (Bott et al., 2005). A large U.S. study found that, for women, there was a strong correlation between diagnoses of major depression and alcohol dependence (Prescott et al., 2000), and alcohol abuse has also been linked to eating disorders, particularly bulimia nervosa (Gadalla \& Piran, 2007). Furthermore, women's suicide ideation, or thoughts of committing suicide, is associated with heavy, frequent drinking (Wilsnack \& Wilsnack, 2014). Several studies have also noted that risk for sexual assault is higher among women who engage in binge drinking, and women with alcohol problems are more likely to report experiencing unwanted sexual advances and harassment (Wilsnack \& Wilsnack, 2014; Pino \& Johnson-Johns, 2009). 


\section{Gender and Health}

As noted, gender norms, similar to social norms, implicitly guide how individuals act, think, and feel. Given the influence of gender roles on behaviors, it has been posited that individuals can express their gender identity through healthrelated practices. Lyons (2009) argues that health behaviors are social practices through which gender identities are constructed and reconstructed, and cultural understandings of femininity and masculinity influence men and women's health behaviors. As such, while health-risking behaviors tend to be associated with masculinity, health-protective behaviors are associated with traditional notions of femininity. For instance, men's enactment of hegemonic masculinity consists of behaving in risky ways such as consuming large amounts of alcohol, engaging in risky sexual behaviors, being violent and emotionally repressed, and refusing professional help (Mahalik et al., 2007). On the other hand, performances of ideal femininity involve self-care, seeking professional help, caring for other members within a family, and overall being nurturing and viewing one's body as vulnerable (Lyons, 2009). Thus, whereas traditional enactments of femininity might be protective of health, traditional notions of masculinity might drive individuals to put their health at risk.

Alcohol consumption, in particular, has been studied as a gendered activity, as researchers have noted that cross-culturally, men drink more often and more heavily than women (Rahav, Wilsnack, Bloomfield, Gmel, \& Kuntsche, 2006). This is most likely because masculinity is characterized by risk-taking and competitiveness (Mahalik et al., 2003; Lyons, 2009), which are traits that lend themselves to heavier 
drinking. A review of international drinking rates, which included mostly European countries, concluded that in all countries sampled, men consumed greater amounts of alcohol than women, and were more likely to drink on a weekly basis. Furthermore, it is stated that women's standing within societies correspond with their rates of drinking, such that in countries where women occupy higher social positions, there are smaller differences between men and women's drinking rates. That is, drinking patterns differentiate men and women's positions in society. Because the gender gap in drinking is a result of gender-based statuses, it is unsurprising that drinking rates between men and women will converge as women achieve increasing equality with men (Rahav et al., 2006). As women occupy more social areas that have traditionally been male-dominated, the "pay off" for this increasing equality is experiencing alcohol's adverse consequences (Rahav et al., 2006; p. i55). As alcohol consumption is deemed a masculine activity, the following review will focus first on masculinity and alcohol use, then femininity and alcohol use, and finally on androgyny.

Masculinity. Given the pronounced link between masculinity and drinking, research has begun to understand gender-relevant factors related to men's drinking. Gender theorists have posited that masculine norms significantly affect men's problematic drinking, and men may endorse masculine traits such as risk-taking, as a way of demonstrating and reinforcing masculinity (Mahalik et al., 2003). For instance, men may report that the ability to consume large amounts of alcohol without fainting or vomiting, is equated with masculinity (Peralta, 2007), demonstrating the extent to which drinking is a gendered activity. 
To further explore the link between salient masculine norms, and alcohol use in U.S. college men, Iwamoto and colleagues (2011) conducted a study among a sample of 776 college men (mean age $=20.24, S D=2.16$ ), of whom the majority identified as Asian American (63\%) or White (19\%). Participants indicated conformity to masculine norms, as well as how frequently they drank to intoxication, and how often they experienced alcohol-related problems, while variables including fraternity status and perceived peer norms were entered as control variables. To examine these associations, the authors used negative binomial regression, as this is an appropriate analytic procedure for count variables, or alcohol outcomes, which tend be skewed and overdispersed (Lewis, Logan, \& Neighbors, 2009; Neal \& Simons, 2007). The results of the study highlighted which distinct masculine norms were significantly associated with drinking to intoxication and alcohol-related problems, even when controlling for the well-established correlates of fraternity status and perceived peer norms. Specifically, the masculine norms Playboy, Risktaking, and Winning were positively associated with drinking to intoxication, while Risk-taking, Playboy, and Self-reliance norms were associated with alcohol-related problems. The authors theorize that these norms reflect traditionally perceived masculine norms, and men who strive to conform to traditional masculinity may engage in more drinking as a way of establishing manhood. Masculine norms of Primacy of Work and Heterosexual Presentation appeared to decrease the risk of drinking to intoxication. These associations may exist because men who prioritize work will not want to jeopardize their work by engaging in binge drinking, while men who are greatly concerned with appearing heterosexual may be concerned with 
managing how others perceived them in general, thus may not want to become intoxicated (Iwamoto et al., 2011).

A study by Iwamoto and Smiler (2013), sought to explain the impact of peer pressure, conformity, and masculine norms, on drinking behaviors among adolescent boys $(N=138)$. Given increasing evidence that girls who endorse masculine norms might be at greater risk for drinking, masculine norms were also assessed within the female sample $(N=124)$. The results indicated that while the relationship between endorsement of masculine norms and alcohol use was stronger for boys, masculine norms were associated with alcohol use for girls, through its effects on peer pressure and general conformity. This study highlights the relevance of masculine norms for girls' drinking behaviors. The authors explored the relationship between masculine norms, peer pressure and conformity, and alcohol use, though a meditational framework, wherein adherence to masculine norms was an internal factor that contributed to susceptibility to peer pressure, and in turn was related to alcohol use behaviors. The study recruited high school seniors (mean age $=17.03$ ), of whom the majority was White (74.1\%). Participants were asked to complete five subscales from the Conformity to Masculine Norms Inventory (Mahalik et al., 2003), including: Emotional control, Winning, Playboy, Risk-Taking, and Heterosexual display. These specific subscales were chosen based on theoretical interest. Participants also completed measures on peer pressure and conformity, and were asked to report the frequency with which they consume various types of alcohol, including beer and wine. The data were analyzed using structural equation modeling (SEM) to determine the relationship between masculine norms, peer pressure and general conformity, and 
alcohol use, and the authors reported the comparative fit index (CFI), Tucker-Lewis fit index (TLI), and root mean square error of approximation (RMSEA). Within the sample, boys reported significantly more alcohol use, $F(1,250),=8.56, p=.004$, higher peer pressure, $F(1,250),=20.14, p=.001$, and greater endorsement of masculine norms. It was also noted that for the girls in the sample, the data fit the model, $C F I=1.00, T L I=1.00, R M S E A=0.01$, and for girls, greater conformity to the masculine norm risk-taking was associated with increased alcohol use. Risk taking also indirectly affected alcohol use, though its effects on peer pressure, while less endorsement of Playboy and Risk-taking norms was indirectly associated with less alcohol use through its effects on general conformity. These findings indicate that understanding masculine norms is relevant for explaining both boys' and girls' drinking behaviors.

Femininity. To date, no published studies have examined multidimensional feminine norms in relation to drinking behaviors, among a sample of U.S. women. However, studies examining feminine norms in relation to drinking among samples of European women have noted that certain norms confer risk for heavier drinking, while others appear to be negatively associated with drinking. Sanchez-Lopez, Cuellar-Flores, and Dresch (2012) examined gender norms in relation to health behaviors, specifically alcohol and cigarette use, as well as chronic disease, among a sample of Spanish men and women, The female sample included 243 participants, whose ages ranged from $18-29$ years, where the mean was 21.35 years old $(S D=$ 1.97). The women were asked to complete the Conformity to Feminine Norms Inventory (Mahalik et al., 2005), as well as various measures on health, and it was 
found that several feminine norms, including Romantic, Sexual Fidelity, and Total endorsement of feminine norms, were inversely associated with alcohol use. Norms related to investing the self in romantic relationships, and adhering to sexual fidelity, were associated with lower alcohol consumption, and explained $13 \%$ of the variance $(F=19.61 ; p<.001)$. The authors posit that these "traditional" feminine norms are protective of alcohol consumption, as they represent conventional notions of femininity, and women who conform to these norms may not want to step outside these conventions. On the other hand, women who do not endorse these traditional norms may engage in more frequent alcohol use, as they may show lower regard for values related to conventional femininity.

Another study in a European sample examined gender norms in relation to alcohol use among Romanian women (Brabete, Sanchez-Lopez, Cuellar-Flores, \& Rivas-Diez, 2013). This sample consisted of 750 people, of whom 489 were women; the age range of the entire sample was between 16 and 72 years, with a mean age of $28.93(S D=10.7)$. To assess women's conformity to feminine norms, the participants were asked to complete the original Conformity to Feminine Norms Inventory (Mahalik et al., 2005); women subsequently completed measures on health-related practices, and results indicated that, similar to the study among Spanish women (Sanchez-Lopez, Cuellar-Flores, \& Dresch, 2012), traditional feminine norms such as Involvement with children, Sexual fidelity, and Modesty, were inversely related with alcohol use. This may demonstrate that alcohol use is incongruent with traditional notions of femininity, therefore women who place importance on these norms may be less likely to consume large quantities of alcohol. 
Androgyny. Given the recent narrowing of the gender difference in alcohol consumption, it is posited that the change of women's traditional feminine norms, and increasing endorsement of traditionally masculine traits, may explain converging drinking rates. This notion is supported by international studies that have found that in societies where women achieve greater equality and approach masculine social status, women and men's drinking rates tend to be more similar (Rahav et al., 2006). Accordingly, this demonstrates that as women attain equality in the sense that they are endorsing more masculine traits, the "pay off" for this increasing equality is drinking and experiencing more alcohol-related problems and consequences.

The endorsement of both masculine and feminine traits is referred to as psychology androgyny, and research has begun to explore this in relation to alcohol consumption. In a sample of German men and women, Möller-Leimkühler, Schwarz, Burtscheidt, and Gaebel (2002) examined gender-role orientation in relation to alcohol use among a sample of 112 patients with alcohol dependence. Gender role orientation was measured with the German version of the Extended Personal Attributes Questionnaire, which categorizes individuals as being the masculine gender-role identity (high in masculinity, low in femininity), the feminine gender-role identity (low in masculinity, high in femininity), androgynous (high in masculinity and femininity), or undifferentiated (low in masculinity and femininity). Results indicated that very few of the participants were androgynous, supporting the notion that androgyny is an unspecified protective factor; alcoholic males tended to be undifferentiated or feminine (74\%) rather than traditionally masculine $(20 \%)$, and alcoholic females tended to be undifferentiated or feminine. The authors conclude 
that that traditional feminine self-concept may be a risk factor for vulnerability to alcohol dependence, and this may be because the traditional female gender role has shifted considerably.

Another study that focused on female undergraduate drinkers, looked specifically at what aspects of femininity and masculinity were associated with women's drinking, and whether women associated being able to drink large amounts of alcohol as "drinking like a guy" (Young et al., 2005). This was a qualitative study, in which participants were pulled from a larger sample of 1,231 women who participated in a web-based 2001 survey from a large public university of approximately 24,000 undergraduate students. Participants were divided into four focus groups consisting of: Stable High drinkers (women who were frequent binge drinkers at two separate time periods), Stable Low (women who were non-binge drinkers), Decreasers (women who were binge drinkers at the first time of the survey, but not at the second time period), Increasers (who were non-binge drinkers at the first time period, but binge drinkers at the second time period), and Sorority members, whose drinking patterns were mixed. There were a total of 42 participants, and the focus group discussions typically lasted 90 to 120 minutes. Observations of the groups included that women in the Stable High group, or women who were frequent binge drinkers, tended to be more socially at ease, as well as friendlier, while participants in the Stable Low group, or women who did not binge-drink at either time period, were more hesitant and cautious during the discussions. In all the discussions, one common theme that emerged was that women who were able to drink large quantities of alcohol felt that this gained positive attention from their male 
peers, and demonstrated that they (the female drinkers) were able to "keep up," and were also more attractive to male peers. Women who binge-drank often also associated their ability to build a tolerance for alcohol with masculine self-control.

Young and colleagues (2005) concluded that women who were frequent binge drinkers were not necessarily drinking to be more like their male peers, but instead saw their drinking as allowing them a special position among male peers, that elevated them above their female peers who were not drinking as much. Therefore, these results may indicate that women's binge drinking is not only enforcing of their heterosexuality (as it helps women feel more attractive to male peers), but also indicative that these women were striving to move away from social positions occupied by other women who were not able to drink competitively with men. It is also noted that while distancing themselves from non-drinking women, frequent binge drinkers in this sample also endorsed certain feminine norms related to thinness and attractiveness. These findings may demonstrate how certain facets of femininity, such as striving to be thin and attractive, confer risk for drinking, as do certain facets of masculinity, such as competitiveness, or striving to win.

\section{Research Hypotheses}

The hypotheses include:

1. Multidimensional masculine norms that have been shown to be risk factors for heavy episodic drinking and alcohol-related problems among men, will also be risk factors for heavy episodic drinking and alcohol-related problems among women, such that these norms will be associated with increased heavy episodic drinking and alcohol-related problems. 
a. "Playboy," or desiring to have multiple sexual partners, will be a robust predictor of increased alcohol use.

b. The norm Risk-taking, or desiring to, and enjoying taking risks, will be positively associated with the outcomes.

c. The winning norm will be positively associated with the outcomes.

d. The norm self-reliance will be positively associated with alcoholrelated problems.

2. Multidimensional masculine norms that have been shown to be protective factors against heavy episodic drinking and alcohol-related problems among men, will also be protective factors against heavy episodic drinking and alcohol-related problems among women, such that they will be associated with decreased heavy episodic drinking and alcohol-related problems.

a. Heterosexual presentation will be negatively associated with the outcomes.

3. Multidimensional feminine norms will serve as risk and protective factors with heavy episodic drinking and alcohol-related problems, such that some norms will be positively associated with these outcomes, while others will be negatively associated with these outcomes.

a. Norms related to maintaining an attractive appearance (Appearance), and desiring a thin physique (Thinness) will be positively associated with the outcome variables.

b. "Traditional" feminine norms will be negatively associated with the outcomes variables. These norms include: 
i. Modesty, or downplaying one's achievements.

ii. Romantic, or investing oneself in romantic relationships.

iii. Sexual fidelity, or only having sex within a monogamous relationship. 


\section{Appendix B}

Demographics

1. Gender
a. Male
b. Female

2. Age

If age is less than 18, then skip to End of Block. If Age is greater than 20, then skip to End of Block

3. Marital Status
a. Single
b. In a committed relationship
c. Divorced
d. Widowed

4. GPA

5. Class Standing
a. Freshman
b. Sophomore
c. Junior
d. Senior

If Sophomore is selected, then skip to End of Block. If Junior is selected, then skip to End of Block. If Senior is selected, then skip to End of Block.

6. Are you an international student?
a. Yes
b. No
c. Other

7. Do you belong to a sorority or fraternity?
a. Yes
b. No 

c. Plan to

8. What is your race/ethnicity?
a. African American/Black
b. Cambodian
c. Caucasian/White
d. Chinese
e. Filipino
f. Iranian
g. Japanese
h. Korean
i. Hispanic/Latino/a
j. Native American
k. Pacific Islander
1. South Asian (i.e. India, Pakistan)
m. Vietnamese
n. Other
o. Biracial

9. Who of the following members were first to be born in the United States?
a. No one in your family. Please specify how long you've been in the U.S.
b. Yourself or your siblings
c. Your parents
d. Your grandparents
e. Your great-grandparents 


\section{Appendix C}

\section{Perceived Peer Use}

For the typical WOMAN, indicate the number of alcoholic drinks you think SHE consumes each day: In a TYPICAL WEEK. (One drink is equivalent to 12 ounces of beer, one shot of liquor either straight or in a mixed drinks, or five ounces of wine):

\begin{tabular}{|l|l|}
\hline & Number of Drinks (1) \\
\hline Monday (1) & \\
\hline Tuesday (2) & \\
\hline Wednesday (3) & \\
\hline Thursday (4) & \\
\hline Friday (5) & \\
\hline Saturday (6) & \\
\hline Sunday (7) & \\
\hline
\end{tabular}

For the typical MAN, indicate the number of alcoholic drinks you think HE consumes each day: In a TYPICAL WEEK. (One drink is equivalent to 12 ounces of beer, one shot of liquor either straight or in a mixed drinks, or five ounces of wine):

\begin{tabular}{|l|l|}
\hline & Number of Drinks (1) \\
\hline Monday (1) & \\
\hline Tuesday (2) & \\
\hline Wednesday (3) & \\
\hline Thursday (4) & \\
\hline Friday (5) & \\
\hline Saturday (6) & \\
\hline Sunday (7) & \\
\hline
\end{tabular}




\section{Appendix D}

Conformity to Masculine Norms Inventory-29 (CMNI-29; Hsu \& Iwamoto, 2014) Thinking about your own actions, feelings and beliefs, please indicate how much you personally agree or disagree with each statement by choosing "Strongly Disagree," "Disagree," "Agree," or "Strongly Agree" to the right of the statement. There are no right or wrong responses to the statements. You should give the responses that most accurately describe your personal actions, feelings and beliefs. It is best if you respond with your first impression when answering.

$$
\begin{gathered}
0=\text { Strongly Disagree } \\
1=\text { Disagree } \\
2=\text { Agree } \\
3=\text { Strongly Agree }
\end{gathered}
$$

\begin{tabular}{|c|c|}
\hline 1. If I could, I would frequently change sexual partners. & $0 \begin{array}{llll}0 & 1 & 2 & 3\end{array}$ \\
\hline 2. I hate asking for help. & $\begin{array}{llll}0 & 1 & 2 & 3\end{array}$ \\
\hline 3. I believe that violence is never justified. & 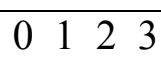 \\
\hline 4. Being thought of as gay is not a bad thing. & 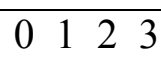 \\
\hline 5. Winning is not my first priority. & 01223 \\
\hline 6. I enjoy taking risks. & $\begin{array}{llll}0 & 1 & 2 & 3\end{array}$ \\
\hline 7. I am disgusted by any kind of violence. & 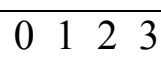 \\
\hline 8. I bring up my feelings when I talk to others. & 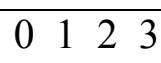 \\
\hline 9. I would be furious if someone thought I was gay. & 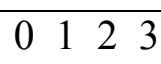 \\
\hline 10. I don't mind losing. & $\begin{array}{llll}0 & 1 & 2 & 3\end{array}$ \\
\hline
\end{tabular}




\begin{tabular}{|c|c|}
\hline 11. I take risks. & 01223 \\
\hline 12. It would not bother me at all if someone thought I was gay. & 01023 \\
\hline 13. I would feel good if I had many sexual partners. & 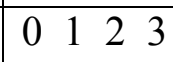 \\
\hline 14. It would be awful if people thought I was gay. & 01223 \\
\hline 15. I like to talk about my feelings. & 01223 \\
\hline 16. I never ask for help. & 012123 \\
\hline 17. More often than not, losing does not bother me. & 0123 \\
\hline 18. I frequently put myself in risky situations. & 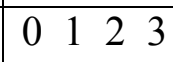 \\
\hline 19. Women should be subservient to men. & 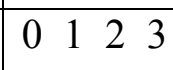 \\
\hline 20. Winning is not important to me. & 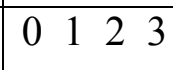 \\
\hline 21. Violence is almost never justified. & 0123 \\
\hline 22. It would be enjoyable to date more than one person at a time. & 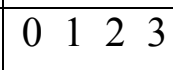 \\
\hline 23. I would feel uncomfortable if someone thought I was gay. & 012123 \\
\hline 24. I tend to share my feelings. & 0123 \\
\hline 25. No matter what the situation, I would never act violently. & 01223 \\
\hline 26. Things tend to be better when men are in charge. & 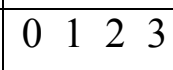 \\
\hline 27. It bothers me when I have to ask for help. & 0123 \\
\hline 28. I love it when men are in charge of women. & 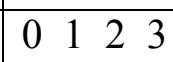 \\
\hline 29. I try to avoid being perceived as gay. & 01223 \\
\hline
\end{tabular}




\section{Appendix E}

Conformity to Feminine Norms Inventory-45 (Parent \& Moradi, 2010)

Thinking about your own actions, feelings and beliefs, please indicate how much you personally agree or disagree with each statement by choosing "Strongly Disagree," "Disagree," "Agree," or "Strongly Agree" to the right of the statement. There are no right or wrong responses to the statements. You should give the responses that most accurately describe your personal actions, feelings and beliefs. It is best if you respond with your first impression when answering.

$$
\begin{gathered}
0=\text { Strongly Disagree } \\
1=\text { Disagree } \\
2=\text { Agree } \\
3=\text { Strongly Agree }
\end{gathered}
$$

\begin{tabular}{|c|c|}
\hline 1. I would be happier if I was thinner. & 01223 \\
\hline 2. It is important to keep your living space clean. & 01223 \\
\hline $\begin{array}{l}\text { 3. I spend more than } 30 \text { minutes a day doing my hair and } \\
\text { makeup. }\end{array}$ & 01223 \\
\hline 4. I tell everyone about my accomplishments. & 01223 \\
\hline 5. I clean my home on a regular basis. & 01223 \\
\hline 6. I feel attractive without makeup. & 01223 \\
\hline 7. I believe that my friendships should be maintained at all costs. & 01223 \\
\hline 8. I find children annoying. & 0123 \\
\hline 9. I would feel guilty if I had a one night stand. & 01223 \\
\hline 10. When I succeed, I tell my friends about it. & 01223 \\
\hline
\end{tabular}




\begin{tabular}{|c|c|}
\hline 11. Having a romantic relationship is essential in life. & 01123 \\
\hline 12. I enjoy spending time making my living space look nice. & $\begin{array}{llll}0 & 1 & 2 & 3\end{array}$ \\
\hline 13. Being nice to others is extremely important. & 01123 \\
\hline 14. I regularly wear makeup. & 01223 \\
\hline 15. I don't go out of my way to keep in touch with friends. & 01223 \\
\hline 16. Most people enjoy children more than I do. & 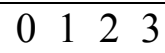 \\
\hline 17. I would like to lose a few pounds. & $0 \begin{array}{lll}0 & 12 & 3\end{array}$ \\
\hline $\begin{array}{l}\text { 18. It is not necessary to be in a committed relationship to have } \\
\text { sex. }\end{array}$ & 01223 \\
\hline 19. I hate telling people about my accomplishments. & 01123 \\
\hline $\begin{array}{l}\text { 20. I get ready in the morning without looking in the mirror very } \\
\text { much. }\end{array}$ & 01223 \\
\hline $\begin{array}{l}\text { 21. I would feel burdened if I had to maintain a lot of } \\
\text { friendships. }\end{array}$ & 01223 \\
\hline 22. I would feel comfortable having casual sex. & 0123 \\
\hline 23. I make it a point to get together with my friends regularly. & 01123 \\
\hline 24. I always downplay my achievements. & 01223 \\
\hline 25. Being in a romantic relationship is important. & 01223 \\
\hline 26. I don't care if my living space looks messy. & 0123 \\
\hline 27. I never wear makeup. & $\begin{array}{llll}0 & 1 & 2 & 3\end{array}$ \\
\hline 28. I always try to make people feel special. & 01223 \\
\hline 29. I am not afraid to tell people about my achievements. & 0123 \\
\hline $\begin{array}{l}\text { 30. My life plans do not rely on my having a romantic } \\
\text { relationship. }\end{array}$ & 01223 \\
\hline 31. I am always trying to lose weight. & $0 \quad 1223$ \\
\hline
\end{tabular}




\begin{tabular}{|c|c|}
\hline 32. I would only have sex with the person I love. & $0 \quad 123$ \\
\hline $\begin{array}{l}\text { 33. When I have a romantic relationship, I enjoy focusing my } \\
\text { energies on it. }\end{array}$ & 01223 \\
\hline $\begin{array}{l}\text { 34. There is no point to cleaning because things will get dirty } \\
\text { again. }\end{array}$ & 01223 \\
\hline 35. I am not afraid to hurt people's feelings to get what I want. & 0123 \\
\hline 36. Taking care of children is extremely fulfilling. & 01223 \\
\hline $\begin{array}{l}\text { 37. I would be perfectly happy with myself even if I gained } \\
\text { weight. }\end{array}$ & 010223 \\
\hline 38. If I were single, my life would be complete without a partner. & 01123 \\
\hline 39. I rarely go out of my way to act nice. & 01123 \\
\hline 40. I actively avoid children. & 01223 \\
\hline 41. I am terrified of gaining weight. & 01123 \\
\hline $\begin{array}{l}\text { 42. I would only have sex if I was in a committed relationship } \\
\text { like marriage. }\end{array}$ & 01223 \\
\hline 43. I like being around children. & 01123 \\
\hline 44. I don't feel guilty if I lose contact with a friend. & 01123 \\
\hline 45. I would be ashamed if someone thought I was mean. & 01223 \\
\hline
\end{tabular}


Appendix F

Heavy Episodic Drinking

For a TYPICAL WEEK, please indicate the number of alcoholic drinks you consumed each day. (One drink is equivalent to 12 ounces of beer, one shot of liquor either straight or in a mixed drink, or five ounces of wine):

\begin{tabular}{|l|l|}
\hline & Number of Drinks (1) \\
\hline Monday (1) & \\
\hline Tuesday (2) & \\
\hline Wednesday (3) & \\
\hline Thursday (4) & \\
\hline Friday (5) & \\
\hline Saturday (6) & \\
\hline Sunday (7) & \\
\hline
\end{tabular}

Answer If Gender Female Is Selected

During the last three months, how many times did you have four or more drinks in a sitting? 


\section{Appendix G}

Brief Young Adult Alcohol Consequences Questionnaire (Kahler, Strong, \& Read, 2005)

\begin{tabular}{|l|l|}
\hline $\begin{array}{l}\text { 1. I have had a hangover (headache, sick stomach) the morning after I had been } \\
\text { drinking. }\end{array}$ & Yes No \\
\hline 2. I have felt very sick to my stomach or thrown up after drinking. & Yes No \\
\hline 3. I have often ended up drinking on nights when I had not planned to drink. & Yes No \\
\hline 4. I have taken foolish risks when I have been drinking. & Yes No \\
\hline 5. I have passed out from drinking. & Yes No \\
\hline $\begin{array}{l}\text { 6. I have found that I needed large amounts of alcohol to feel any effect, or that I } \\
\text { could no longer get tipsy on the amount that used to get me tipsy or drunk. }\end{array}$ & Yes No \\
\hline 7. When drinking, I have done impulsive things I regretted later. & Yes No \\
\hline 8. I've not been able to remember large stretches of time while drinking heavily. & Yes No \\
\hline 9. I have driven a car when I knew I had too much to drink to drive safely. & Yes No \\
\hline $\begin{array}{l}\text { 10. I have not gone to work or missed classes at school because of drinking, a } \\
\text { hangover, or illness caused by drinking. }\end{array}$ & Yes No \\
\hline 11. My drinking has gotten me into sexual situations I later regretted. & Yes No \\
\hline 12. I have found it difficult to limit how much I drink. & Yes No \\
\hline 13. I have become very rude, obnoxious, or insulting after drinking. & Yes No \\
\hline 14. I have woken up in an unexpected place after heavy drinking. & Yes No \\
\hline 15. I have felt badly about myself because of my drinking. & Yes No \\
\hline 16. I have had less energy or felt tired because of my drinking. & Yes No \\
\hline 17. The quality of my work or school work has suffered because of my drinking. \\
\hline 18. I have spent too much time drinking. & Yes No \\
\hline
\end{tabular}




\begin{tabular}{|l|l|}
\hline 19. I have neglected my obligations to family, work, or school because of drinking. & Yes No \\
\hline $\begin{array}{l}\text { 20. My drinking has created problems between myself and my } \\
\text { boyfriend/girlfriend/spouse, parents, or other near relatives. }\end{array}$ & Yes No \\
\hline 21. I have been overweight because of drinking. & Yes No \\
\hline 22. My physical appearance has been harmed by my drinking. & Yes No \\
\hline 23. I have felt like I needed a drink after I'd gotten up (that is, before breakfast). & Yes No \\
\hline
\end{tabular}




\section{Bibliography}

Acker, C. (1986). Neuropsychological deficits in alcoholics: The relative contributions of gender and drinking history. British Journal of Addiction, 81(3), 395-403.

Baer, J.S., Stacy, A., \& Larimer, M. (1991). Biases in the perception of drinking norms among college students. Journal of Studies on Alcohol, 52(6), 580-586.

Barker, G., Ricardo, C., Nascimento, M., Olukoya, A., \& Santos, C. (2010).

Questioning gender norms with men to improve health outcomes: Evidence of impact. Global Public Health, 5(5), 539-553.

Bem, S.L. (1974). The measurement of psychological androgyny. Journal of Consulting and Clinical Psychology, 42, 155-162. doi: 10.1037/h0036215

Bordo, S. (1993). Unbearable Weight: Feminism, Western Culture and the Body. Berkeley, CA: University of California press.

Borsari, B., Murphy, J.G., \& Barnett, N.P. (2007). Predictors of alcohol use during the first year of college: Implications for prevention. Addictive Behaviors, 32(10), 2062-2086.

Brabete, A.C., Sanchez-Lopez, M., Cuellar-Flores, I., \& Rivas-Diez, R. (2013). The impact of

gender norms on alcohol and tobacco use at Romanians. Procedia - Social and Behavioral Sciences, 78, 230-234.

Brown, T.A. (2012). Confirmatory factor analysis for applied research. Guilford 
Press.

Capone, C., Wood, M.D., Borsari, B., \& Laird, R.D. (2007). Fraternity and sorority involvement, social influences, and alcohol use among college students: A prospective examination. Psychology of Addictive Behavior, 21(3), 316-327.

Corbin, W.R., Iwamoto, D.K., \& Fromme, K. (2011). Broad social motives, alcohol use, and related problems: Mechanisms of risk from high school through college. Addictive Behaviors, 36(3), 222-230. doi:

10.1016/j.addbeh.2010.11.004

Courtenay, W.H. (2000). Constructions of masculinity and their influence on men's well-being: A theory of gender and health. Social Science \& Medicine, 50, $1385-1401$.

Dollinger, S.J., \& Malmquist, D. (2009). Reliability and validity of single-item selfreports: With special relevant to college students' alcohol use, religiosity, study, and social life. The Journal of General Psychology, 136(3), 231-241.

DuRant, R.H., McCoy, T.P., Champion, H., Parries, M.T., Mitra, A., Martin, B.A., et al. (2008). Party behaviors and characteristics and serial drunkenness among college students. Journal of Studies on Alcohol and Drugs, 69(1), 91-99.

Enders, C.K., \& Bandalos, D.L. (2001). The relative performance of full information maximum likelihood estimation for missing data in structural equation models. Structural Equation Modeling, 8, 430-457.

Fleming, P.J., Lee, J.G.L., \& Dworkin, S.L. (2014). "Real men don't”: Constructions 
of masculinity and inadvertent harm in public health interventions. American Journal of Public Health, 104(6), 1029-1035.

Frezza, M., di Padova, C., Pozatto, G., Terpin, M., Baraona, E., \& Lieber, C.S. (1990). High blood alcohol levels in women: The role of decreased gastric alcohol dehydrogenase activity and first-pass metabolism. New England Journal of Medicine, 322, 95-99.

Gilbert, L.A. (1981). Toward mental health: The benefits of psychological androgyny. Professional Psychology, 12(1), 29-38.

Hingson, R.W., Heeren, T., \& Zakocs, R.C. (2002). Magnitude of alcohol-related mortality and morbidity among U.S. college students ages 18-24. Journal of Studies on Alcohol, 63, 136-144.

Hingson, R., Heeren, T., Zakocs, R., Winter, M., \& Wechsler, H. (2003). Age of first intoxication, heavy drinking, driving after drinking and risk of unintentional injury among U.S. college students. Journal of Studies on Alcohol, 64(1), 2331.

Hingson, R., Heeren, T., Winter, M., \& Wechsler, H. (2005). Magnitude of alcoholrelated mortality and morbidity among U.S. college students ages $18-24$ : Changes from 1998 to 2001. Annual Review of Public Health, 26, 259 -279. doi: $10.1146 /$ annurev.publhealth.26.021304.144652

Hingson, R., \& White, A. (2014). New research findings since the 2007 Surgeon General's Call to Action to Prevent and Reduce Underage Drinking: A 
review. Journal of Studies on Alcohol and Drugs, 75(1), 158-169.

Hopwood, C.J., \& Donnellan, M.B. (2010). How should the internal structure of personality inventories be evaluated? Personality and Social Psychology Review, 14(3), 332-346. doi: 10.1177/1088868310361240

Hsu, K., \& Iwamoto, D.K. (2014). Testing for measurement invariance in the conformity to Masculine Norms-46 across White and Asian American college men: Development and validity of the CMNI-29. Psychology of Men \& Masculinity, 15(4), 397-406. doi: 10.1037/a0034548

Hu, L.T., \& Bentler, P.M. (1999). Cutoff criteria for fit indexes in covariance structure analysis: Conventional criteria versus new alternatives. Structural Equation Modeling: A Multidisciplinary Journal, 6(1), 1-55.

Hutton, F.C. (2004). 'Up for it, mad for it?' Women, drug use, and participation in club scenes. Health Risk and Society, 6(3), 223-237.

Iwamoto, D.K., Cheng, A., Lee, C.S., Takamatsu, S., \& Gordon, D. (2011). "Maning" up and getting drunk: The role of masculine norms, alcohol intoxication and alcohol-related problems among college men. Addictive Behaviors, 36(9), 906-911. doi:10.1016/j.addbeh.2011.04.005.

Iwamoto, D.K., \& Smiler, A.P. (2013). Alcohol makes you macho and helps you make friends: The role of masculine norms and peer pressure in adolescent boys' and girls' alcohol use. Alcohol Use \& Misuse, 48(5), 223-237.

Iwamoto, D.K., Corbin, W., Lejuez, C., \& MacPherson, L. (2014). College men and 
alcohol use: Positive alcohol expectancies as a mediator between distinct masculine norms and alcohol use. Psychology of Men \& Masculinity, 15(1), 29-39.

Iwamoto, D.K., Grivel, M., Cheng, A., Clinton, L., \& Kaya, A. (2015). Asian American women and alcohol-related problems: The role of multidimensional feminine norms. Journal of Immigrant and Minority Health. doi: $10.1007 / \mathrm{s} 10903-015-0159-3$

Jones, B.M., \& Jones, M.K. (1976). Alcohol effects in women during the menstrual cycle. Annals of the New York Academy of Sciences, 273(1), 576-597.

Kahler, C.W., Strong, D.R., \& Read, J.P. (2005). Toward efficient and comprehensive measurement of the alcohol problems continuum in college students: The Brief Young Adult Alcohol Consequences Questionnaire. Alcoholism: Clinical and Experimental Research, 29(7), 1180-1189. doi: 10.1097/01.ALC.0000171940.95813.A5

Keyes, K.M., Grant, B.F., \& Hasin, D.S. (2008). Evidence for a closing gender gap in alcohol use, abuse, and dependence in the United States population. Drug and Alcohol Dependence, 93, 21-29.

Keyes, K.M., Martins, S.S., Blanco, C., \& Hasin, D.S. (2010). Telescoping and gender differences in alcohol dependence: New evidence from two national surveys. The American Journal of Psychiatry, 167(8), 969-976. doi: 10.1176/appi.ajp.2009.09081161 
Labrie, J.W., Cail, J., Hummer, J.F., Lae, A., \& Neighbors, C. (2009). What men want: The role of reflective opposite-sex normative preferences in alcohol use among college women. Psychology of Addictive Behavior, 23, 157-162.

Larimer, M.E., Turner, A.P., Mallett, K.A., \& Geisner, I.M. (2004). Predicting drinking behavior and alcohol-related problems among fraternity and sorority members: Examining the role of descriptive and injunctive norms. Psychology of Addictive Behaviors, 18(3), 203-212.

Lee, C., \& Owens, R.G. (2002). The Psychology of Men's Health. Buckingham, UK: Open University Press.

Lemle, R., \& Mishkind, M.E. (1989). Alcohol and masculinity. Journal of Alcohol Abuse Treatment, 6(4), 213-222.

Liu, W. M., \& Iwamoto, D. K. (2007). Conformity to masculine norms, Asian values, coping strategies, peer group influences and alcohol use among Asian American men. Psychology of Men \& Masculinity, 8, 25-39. doi:10.1037/1524-9220.8.1.25

Locke, B. D., \& Mahalik, J. R. (2005). Examining masculinity norms, problem drinking, and athletic involvement as predictors of sexual aggression in college men. Journal of Counseling Psychology, 52, 279- 283. doi:10.1037/0022-0167.52.3.279

Loft, S., Olesen, K.L., \& Dossing, M. (1987). Increased susceptibility to liver disease in relation to alcohol consumption in women. Scandinavian Journal of 
Gastroenterology, 22, 1251-1256.

Lyons, A.C., \& Willott, S.A. (2008). Alcohol consumption, gender identities, and women's changing social position. Sex Roles, 59, 649-712. doi: 10/1007/s11199-008-9475-6.

Lyons, A.C. (2009). Masculinities, femininities, behavior, and health. Social and Personality Psychology Compass, 3/4, 394-412. doi: 10.111/j.17519004.2009.00192.x

Mahalik, J. R., Locke, B. D., Ludlow, L. H., Diemer, M. A., Scott, R. P., Gottfried, M., \& Freitas, G. (2003). Development of the Conformity to Masculine Norms Inventory. Psychology of Men \& Masculinity, 4, 3-25. doi:10.1037/1524-9220.4.1.3

Mahalik, J.R., Morray, E.B., Coonerty-Femiano, A., Ludlow, L.H., Slattery, S.M., \& Smiler, A. (2005). Development of the conformity to feminine norms inventory. Sex Roles, 52(7/8), 417-435. doi:10.1007/s11199-005-3709-7

Mahalik, J.R., Burns, S.M., \& Syzdek, M. (2007). Masculinity and perceived normative health behaviors as predictors of men's health behaviors. Social Science \& Medicine, 64(11), 2201-2209.

Marczinski, C.A., Abroms, B.D., Van Selst, M., \& Fillmore, M.T. (2005). Alcoholinduced impairment of behavioral control: Differential effects on engaging vs. disengaging responses. Psychopharmacology, 182, 452-459.

Marsh, H.W., Balla, J.R., \& Hau, K.T. (1996). An evaluation of incremental fit 
indices: A clarification of mathematical and empirical properties. In G.A. Marcoulides \& R.E. Schumacker (Eds.), Advanced structural equation modeling: Issues and techniques (pp. 315-353). Mahwah, NJ: Lawrence Erlbaum.

Midanik, L. (1988). Validity of self-report alcohol use: A literature review and assessment. British Journal of Addiction, 83, 1019-1029.

Möller-Leimkühler, A. M., Schwarz, R., Burtscheidt, W., \& Gaebel, W. (2002). Alcohol dependence and gender-role orientation. European Psychiatry,17, 18.

Neal, D.J., \& Simons, J.S. (2007). Inference in regression models of heavily skewed alcohol use data: A comparison of ordinary least squares, generalized linear models, and bootstrap resampling. Psychology of Addictive Behaviors, 21(4), 441-452. doi:10.1037/0893-164X.21.4.441

Nolen-Hoeksema, S., \& Hilt, L. (2006). Possible contributors to gender differences in alcohol use and problems. The Journal of General Psychology, 133(4), 357374.

O’Brien, K.M., \& Fassinger, R.E. (1993). A causal model of the career orientation and career choice of adolescent women. Journal of Counseling Psychology, 40, 456-469.

Olinksy, A., Chen, S., \& Harlow, L. (2003). The comparative efficacy of imputation methods for missing data in structural equation modeling. European Journal 
of Operational Research, 151, 53-79.

Parent, M.C., \& Moradi, B. (2009). Confirmatory factor analysis of the Conformity to Masculine Norms Inventory and development of the Conformity to Masculine Norms Inventory-46. Psychology of Men \& Masculinity, 10(3), 175-189.

Parent, M.C., \& Moradi, B. (2010). Confirmatory factor analysis of the Conformity to Feminine Norms Inventory and development an abbreviated version: The CFNI-45. Psychology of Women Quarterly, 34(1), 97-109.

Parent, M.C., \& Smiler, A.P. (2013). Metric invariance of the Confirmity to Masculine Norms Inventory-46 among women and men. Psychology of Men \& Masculinity, 14(3), 324-328. doi: 10/1037/a0027642

Parks, K.A., Miller, B.A., Collins, R.L., \& Zeets-Zanatta, L. (1998). Women's descriptions of drinking in bars: Reasons and risks. Sex Roles, 38, 701-716.

Parks, K.A., \& Fals-Stewart, W. (2004). The temporal relationship between college women's alcohol consumption and victimization experiences. Alcoholism: Clinical and Experimental Research, 28, 625-629.

Pedersen, E.R., Grow, J., Duncan, S., Neighbors, C., \& Larimer, M.E. (2012). Concurrent validity of an online version of the Timeline Followback assessment. Psychology of Addictive Behaviors, 26(3), 672-677.

Peralta, R.L. (2007). College alcohol use and the embodiment of hegemonic masculinity among European American men. Sex Roles, 56, 741-756.

Perry, J.L., Nicholls, A.R., Clough, P.J., \& Crust, L. (2015). Assessing model fit: Caveats and recommendations for confirmatory factor analysis and 
exploratory structural equation modeling. Measurement in Physical Education and Exercise Science, 19, 12-21. doi: 10.1080/1091367X.2014.952370

Rahav, G., Wilsnack, R., Bloomfield, K., Gmel, G., \& Kuntsche, S. (2006). The influence of societal level factors on men's and women's alcohol consumption and alcohol problems. Alcohol and Alcoholism, 41, 147-155.

Ricciardelli, L.A., Connor, J.P., Williams, R.J., \& Young, R.M. (2001). Gender stereotypes and drinking cognitions as indicators of moderate and high risk drinking among young women and men. Drug and Alcohol Dependence, 61(2), 129-136.

Saltonstall, R. (1993). Healthy bodies, social bodies: Men's and women's concepts and practices of health in everyday life. Social Science \& Medicine, 36, 7-14.

Sanchez-Lopez, M., Flores, I., \& Dresch, V. (2012). The impact of gender roles on health. Women \& Health, 52(2), 182-196.

Schlomer, G.L., Bauman, S., \& Card, N.A. (2010). Best practices for missing data management in counseling psychology. Journal of Counseling Psychology, 57(1), 1-10. doi: 10.1037/a0018082

Sher, K.J., Bartholow, B.D., \& Nanda, S. (2001). Short-and long-term effects of fraternity and sorority membership on heavy drinking: A social norms perspective. Psychology of Addictive Behaviors, 15(1), 42-51.

Simonen, J. (2013). Accepted, desired and ashamed: Images of female alcohol use 
and drinking-related gender orders described by Finnish women of different ages. Nordic Studies on Alcohol and Drugs, 30, 201-226.

Smiler, A.P. (2004). Thirty years after the discovery of gender: Psychological concepts and measures of masculinity. Sex Roles, 50, 15-26. doi: $10.1007 / \mathrm{s} 11199-006-9045-8$

Smith, G.T., McCarthy, D.M., \& Goldman, M.S. (1995). Self-reported drinking and alcohol-related problems among early adolescents: Dimensionality and validity over 24 months. Journal of Studies on Alcohol, 54(4), 383-394.

Sobell, L.C., \& Sobell, M.B. (1995). Alcohol consumption measures. Assessing alcohol problems: A guide for clinicians and researchers, 4, 55-76.

Steinfeldt, J.A., Zakrajsek, R., Carter, H., \& Steinfeldt, M.C. (2011). Conformity to gender norms among female student-athletes: Implications for body image. Psychology of Men \& Masculinity, 12(4). 401-416. doi: 10.1037/a0023634

Taylor, M.C., \& Hall, J.A. (1982). Psychological androgyny: Theories, methods, and conclusions. Psychological Bulletin, 92(2), 347-366.

U.S. Department of Health and Human Services. (2007). The Surgeon General's call to action to prevent and reduce underage drinking. Rockville, MD: Office of the Surgeon General. Retrieved from http://www.surgeongeneral.gov/library/calls/underagedrinking/ calltoaction.pdf 
Van Gundy, K., Schieman, S., Kelley, M., \& Rebellon, C.J. (2005). Gender role orientation and alcohol use among Moscow and Toronto adults. Social Science and Medicine, 61(11), 2317-2330.

Verdejo-Garcia, A., Lawrence, A.J., \& Clark, L. (2008). Impulsivity as a vulnerability marker for substance use disorders: Review of findings from high-risk research, problem gamblers and genetic association studies. Neuroscience \& Biobehavioral Reviews, 32(4), 777-810.

Wechsler, H., \& Isaac, B. (1992). Binge drinkers at Massachusetts colleges: Prevalence, drinking style, time trends, and associated problems. Journal of the American Medical Association, 267(21), 2929-2931.

Wechsler, H., Dowdall, G.W., Davenport, A., \& Rimm, E.B. (1995). A genderspecific measure of binge drinking among college students. American Journal of Public Health, 85(7), 982-985.

Wechsler, H., Lee, J.E., Kuo, M., Seibring, M., Nelson, T.F., \& Lee, H. (2002). Trends in college binge drinking during a period of increased prevention efforts. Findings from 4 Harvard school of Public Health College Alcohol Study surveys: 1993-2001. Journal of American College Health, 50, 203-217.

Wechsler, H., Kuh, G., \& Davenport, A.E. (2009). Fraternities, sororities and binge drinking: Results from a national study of American colleges. Journal of Student Affairs Research and Practice, 46(3), 763-784.

Wilsnack, R. W., Vogeltanz, N. D., Wilsnack, S. C., \& Harris, T. R. (2000). Gender 
differences in alcohol consumption and adverse drinking consequences:

Cross-cultural patterns. Addiction, 95(2), 251-265.Wilsnack, S.C., \&

Wilsnack, R.W. (2014). Focus on: Women and the costs of alcohol use.

Alcohol Research, 35(2), 219-228.

Woodhill, B.M., \& Samuels, C.A. (2004). Desirable and undesirably androgyny: A prescription for the twenty-first century. Journal of Gender Studies, 13(1), 1528. doi: $10.1080 / 0958923032000184943$

Worthington, R.L., \& Whittaker, T.A. (2006). Scale development research: A content analysis and recommendations for best practices. The Counseling Psychologist, 34(6), 806-838. doi:10.1177/0011000006288127

Young, A. M., Morales, M., McCabe, S. E., Boyd, C. L., \& D’Arcy, H. (2005). Drinking like a guy: Frequent binge drinking among undergraduate women. Alcohol Use \& Misuse, 40, 241-267. doi:10.1081/JA-200048464 